\title{
Synaptic Inputs Compete during Rapid Formation of the Calyx of Held: A New Model System for Neural Development
}

\author{
Paul S. Holcomb, ${ }^{1}$ Brian K. Hoffpauir, ${ }^{1}$ Mitchell C. Hoyson, ${ }^{1}$ Dakota R. Jackson, ${ }^{1}$ Thomas J. Deerinck, ${ }^{4}$ Glenn S. Marrs, ${ }^{1}$ \\ Marlin Dehoff, ${ }^{1}$ Jonathan $\mathrm{Wu},{ }^{2}$ Mark H. Ellisman, ${ }^{4,5}$ and George A. Spirou ${ }^{1,2,3}$ \\ ${ }^{1}$ Center for Neuroscience, West Virginia University School of Medicine, Morgantown, West Virginia 26506-9303, ${ }^{2}$ Department of Otolaryngology, West \\ Virginia University School of Medicine, Morgantown, West Virginia 26506-9303, ${ }^{3}$ Department of Physiology and Pharmacology, West Virginia University \\ School of Medicine, Morgantown, West Virginia 26506-9303, ${ }^{4}$ National Center for Microscopy and Imaging Research, University of California, San Diego, \\ California 92092-0608, and 5Department of Neuroscience, University of California, San Diego, California 92092-0608
}

Hallmark features of neural circuit development include early exuberant innervation followed by competition and pruning to mature innervation topography. Several neural systems, including the neuromuscular junction and climbing fiber innervation of Purkinje cells, are models to study neural development in part because they establish a recognizable endpoint of monoinnervation of their targets and because the presynaptic terminals are large and easily monitored. We demonstrate here that calyx of Held $(\mathrm{CH})$ innervation of its target, which forms a key element of auditory brainstem binaural circuitry, exhibits all of these characteristics. To investigate $\mathrm{CH}$ development, we made the first application of serial block-face scanning electron microscopy to neural development with fine temporal resolution and thereby accomplished the first time series for 3D ultrastructural analysis of neural circuit formation. This approach revealed a growth spurt of added apposed surface area (ASA) $>200 \mu \mathrm{m}^{2} / \mathrm{d}$ centered on a single age at postnatal day 3 in mice and an initial rapid phase of growth and competition that resolved to monoinnervation in two-thirds of cells within $3 \mathrm{~d}$. This rapid growth occurred in parallel with an increase in action potential threshold, which may mediate selection of the strongest input as the winning competitor. ASAs of competing inputs were segregated on the cell body surface. These data suggest mechanisms to select "winning" inputs by regional reinforcement of postsynaptic membrane to mediate size and strength of competing synaptic inputs.

\section{Introduction}

The overproduction of synaptic connections and subsequent pruning is a common theme in nervous system development (Purves and Lichtman, 1980). Model systems to study these events include the neuromuscular junction (NMJ; Wu et al., 2010), climbing fiber innervation of Purkinje cells (CF:PC; Watanabe and Kano, 2011), and retinal ganglion cell innervation of the dorsal lateral geniculate nucleus (RGC:dLGN; Hong and Chen, 2011) because nerve terminals are large and easily identified, and because the end point of 1:1 or few-to-one innervation ratio is easily quantified. In each of these systems, innervation begins as contact by multiple small inputs, proceeds through an

Received March 12, 2013; revised May 24, 2013; accepted June 1, 2013.

Author contributions: P.S.H., B.K.H., G.S.M., M.H.E., and G.A.S. designed research; P.S.H., B.K.H., M.H., D.R.J., T.J.D., G.S.M., M.D., J.W., and G.A.S. performed research; P.S.H., B.K.H., M.C.H., D.R.J., G.S.M., J.W., M.H.E., and G.A.S. analyzed data; P.S.H. and G.A.S. wrote the paper.

This work was supported by National Institutes of Health (NIH) Grant R01 DC007695 to G.A.S., NIH Grant F32 DC008730 to B.K.H., NIH Grant F32 DC105462 to G.S.M., NIH/National Institute of General Medical Sciences (NIGMS) Grant CoBRE P30 GM103503 to the WVU Center for Neuroscience, and NIH/NIGMS Grant P41 GM103412 to the National Center for Microscopy and Imaging Research. We thank an additional 21 tracers who segmented neurons for $3 \mathrm{D}$ reconstruction and analysis, Brian Pope for tissue preparation, and Gerry Hobbs for assistance with statistical analysis. Bill Mallers contributed original scores for videos. We appreciate the insightful comments of two anonymous reviewers.

The authors declare no competing financial interests.

Correspondence should be addressed to George A. Spirou, Center for Neuroscience, West Virginia University School of Medicine, One Medical Center Drive, Morgantown, WV 26506-9303. E-mail: gspirou@hsc.wvu.edu.

DOI:10.1523/JNEUROSCI.1087-13.2013

Copyright $\odot 2013$ the authors $\quad 0270-6474 / 13 / 3312954-16 \$ 15.00 / 0$ early competitive stage whereby several inputs strengthen, and completes by final pruning to, in most cases, a single "winning" input.

Another neural connection characterized by monoinnervation is the calyx of Held contact with principal cells of the medial nucleus of the trapezoid body $(\mathrm{CH}: \mathrm{MNTB})$, but there is uncertainty about the prevalence of competition among synaptic inputs (Hoffpauir et al., 2006; Rodríguez-Contreras et al., 2008) and, therefore, whether it exhibits the hallmark developmental features of other neural systems (Borst and Soria van Hoeve, 2012). This typically mammalian neural connection is part of massive binaural convergence circuitry in the auditory brainstem (Warr, 1972). Light microscopic techniques established rapid growth of $\mathrm{CHs}$ in rats over several days during the first postnatal week (Kandler and Friauf, 1993; Rodríguez-Contreras et al., 2008). In mice, rapid growth in synaptic currents occurred in a narrow temporal window between postnatal day (P) 2 and P4. Both serial section electron microscopy and minimal stimulation physiological techniques in brain slices revealed only a small percentage of MNTB neurons innervated by multiple large inputs at P4 (2 of 19, $11 \%$; 4 of 29, 17\%, respectively; Hoffpauir et al., 2006). Electrophysiological counting techniques revealed multiple small inputs onto most cells from late embryonic and younger postnatal ages (Rodríguez-Contreras et al., 2008; Hoffpauir et al., 2010). Therefore, it seems plausible that the $\mathrm{CH}: \mathrm{MNTB}$ also passes through hallmark developmental stages found in other neural systems.

To objectively assay the dynamics of calyx formation, we used an anatomical approach because physiological counting tech- 
niques provide an underestimate of convergent synaptic inputs due to sectioning of axons in brain slice preparations. Also, convergent inputs may share stimulation thresholds and be unresolvable. Serial block-face scanning electron microscopy (SBEM) provides high resolution to identify neuronal contacts and accurately registers cellular ultrastructure through large tissue volumes (Denk and Horstmann, 2004; Briggman et al., 2011). SBEM and related techniques were developed to generate maps of neural circuits, called connectomes, with the eventual objective of comparing brains among normal and pathological states (Kleinfeld et al., 2011). Here we make the first application of these technologies to the developing brain with fine temporal resolution to reveal changing neural connections across the age range critical for calyx growth (P2-P9). We demonstrate early exuberant innervation, establish that competition is a common process, and pinpoint $\mathrm{P} 3$ as a uniquely active day in $\mathrm{CH}$ growth, during which cell apposition areas increase at a rate exceeding 200 $\mu \mathrm{m}^{2} / \mathrm{d}$. These data provide metrics for $\mathrm{CH}$ growth dynamics more precise than for other model systems and exemplify utility of the CH:MNTB system for studies of synaptogenesis with relevance to other neural systems throughout the brain.

\section{Materials and Methods}

Ethical approval. All procedures involving animals were approved by the West Virginia University (WVU) Institutional Animal Care and Use Committee and were in accordance with policies of the United States Public Health Service.

Animals. A breeding colony of mice (FVB/NJ; The Jackson Laboratory; or FVB/NCr; National Cancer Institute) was maintained within the vivarium at West Virginia University School of Medicine. Timed pregnancies were performed by pairing mice overnight. Assuming fertilization occurred around midnight, gestation time was $\sim 19 \mathrm{~d}$ [embryonic day (E) 0-E18] with birth typically occurring overnight. Animals were checked twice daily, so ages denoted herein are accurate to within $12 \mathrm{~h}$.

Tissue processing for SBEM. Unless otherwise indicated, all reagents were purchased from Sigma-Aldrich. A single mouse of either sex was used at each age (P2, P3, P4, P6, and P9) with the exception of P2, where a second mouse was used to check data consistency. This second P2 mouse, as well as the P3 and P4 mice, were littermates; the mice used for P6 and P9 were littermates from a separate litter. Key image features were also compared and were consistent with those from separate animals in a different study where serial sections were imaged by transmission electron microscopy (Hoffpauir et al., 2006). Each mouse was anesthetized and perfused with normal Ringer's solution containing xylocaine $(0.2$ $\mathrm{mg} / \mathrm{ml})$ and heparin $(20 \mathrm{U} / \mathrm{ml})$ for $2 \mathrm{~min}$ at $35^{\circ} \mathrm{C}$ followed by $0.15 \mathrm{M}$ cacodylate buffer containing 2.5\% glutaraldehyde (Polysciences), $2 \%$ formaldehyde (Fisher Scientific) with $2 \mathrm{~mm}$ calcium chloride at $35^{\circ} \mathrm{C}$ for $5 \mathrm{~min}$. Brains were removed from the skull and postfixed for an additional $18 \mathrm{~h}$ on ice in the same solution. Brain tissue was cut into $200-\mu \mathrm{m}-$ thick sections in the coronal plane using a vibratome (Ted Pella) in ice-cold $0.15 \mathrm{~m}$ cacodylate buffer containing $2 \mathrm{~mm}$ calcium chloride, then washed for $30 \mathrm{~min}$ in the same solution. The MNTB was identified in free-floating sections using a dissecting microscope and the superior olivary complex containing the MNTB, with surrounding tissue $(\sim 1.5 \times$ $1.5 \mathrm{~mm}$ ), was dissected from the tissue. The tissue was photographed and the location of the MNTB was mapped relative to contours of the brain surface and cut edges of the tissue block. A solution containing 3\% potassium ferrocyanide (Electron Microscopy Sciences) in $0.3 \mathrm{M}$ cacodylate buffer with $4 \mathrm{~mm}$ calcium chloride was combined with an equal volume of $4 \%$ aqueous osmium tetroxide and added immediately to the tissue for $1 \mathrm{~h}$ at room temperature (RT). Tissue was processed sequentially through filtered $1 \%$ thiocarbohydrazide (Electron Microscopy Sciences; all water was nanopure filtered; Nanopure Diamond, Barnstead International) for $20 \mathrm{~min}$ at $\mathrm{RT}, 2 \%$ osmium for $30 \mathrm{~min}$ at $\mathrm{RT}$, and $1 \%$ uranyl acetate overnight at $4^{\circ} \mathrm{C}$ following triple rinses in $\mathrm{H}_{2} \mathrm{O}$ for 5 min each between each step. Tissue was triple rinsed in $\mathrm{H}_{2} \mathrm{O}$ at RT for $30 \mathrm{~min}$. A lead aspartate solution was prepared ( $0.066 \mathrm{~g}$ lead nitrate; Electron Micros-
Table 1. Image volumes and analysis ${ }^{a}$

\begin{tabular}{|c|c|c|c|c|c|}
\hline $\begin{array}{l}\text { Postnatal } \\
\text { day }\end{array}$ & $\begin{array}{l}\text { Tissue dimensions } \\
(\mu \mathrm{m})\end{array}$ & $\begin{array}{l}\text { Pixel size } \\
(\mathrm{nm})\end{array}$ & $\begin{array}{l}\text { Tissue volume } \\
\left(\mu \mathrm{m}^{3}\right)\end{array}$ & $\begin{array}{l}\text { Number of cells } \\
\text { analyzed }\end{array}$ & $\begin{array}{l}\text { Number of cells } \\
\text { in volume }\end{array}$ \\
\hline 2 & 124.8 & 5.7 & 965,473 & 21 & 71 \\
\hline 3 & $96 \times 84 \times 50.2$ & 12.0 & 404,813 & 37 & 37 \\
\hline 4 & $80 \times 80 \times 59.9$ & 10.0 & 383,360 & 18 & 18 \\
\hline 6 & $98 \times 78.4 \times 68$ & 4.9 & 522,458 & 43 & 43 \\
\hline 9 & $153.6 \times 115.2 \times 59.2$ & 4.8 & $1,047,527$ & 66 & 66 \\
\hline
\end{tabular}

${ }^{a}$ Dimensions are formatted as width $\times$ height $\times$ depth. Pixel dimensions reported as one side of a square pixel. Cells were considered to be within the volume if all portions of the cell body, nucleus, and identified inputs were completely enclosed within the volume. Of the 185 cells analyzed, 57 of these cells were qualitatively determined to have a single dominant input (P9) and the remaining 128 cells were quantitatively analyzed using ASA.

copy Sciences), dissolved in $10 \mathrm{ml}$ of $0.003 \mathrm{M}$ aspartic acid solution, $\mathrm{pH}$ adjusted to 5.5 with $1 \mathrm{~N} \mathrm{KOH}$, warmed in a $60^{\circ} \mathrm{C}$ oven for $30 \mathrm{~min}$, and filtered. Sections were placed into filtered lead aspartate solution in the $60^{\circ} \mathrm{C}$ oven for $30 \mathrm{~min}$. The tissue was rinsed five times for 3 min in $\mathrm{H}_{2} \mathrm{O}$ and then dehydrated through graded alcohols into acetone and flatembedded in Durcopan resin (Electron Microscopy Sciences) between mylar strips and placed in a $60^{\circ} \mathrm{C}$ oven for $48 \mathrm{~h}$. Tissue samples were photographed and shipped to the National Center for Microscopy and Imaging Research (University of California San Diego) for imaging. The MNTB was identified by comparing photographs of tissue before and after staining.

SBEM imaging. Resin-embedded tissues were mounted on aluminum specimen pins (Gatan) using cyanoacrylic glue and precision trimmed with a glass knife to a rectangle $\sim 0.5 \times 0.75 \mathrm{~mm}$ so that tissue was exposed on all four sides. Silver paint (Ted Pella) was used to electrically ground the edges of the tissue block to the aluminum pin. The entire specimen was then sputter coated with a thin layer of gold/palladium to enhance conductivity. After the block was faced with a 3View ultramicrotome unit (Gatan) to remove the top layer of gold/palladium, the tissue morphology became visible by back-scattered electron detector imaging and the remaining coating on the edges of the block served to reduce charging. A low-magnification image $(\sim 500 \times)$ was collected to identify the MNTB and midline and to target the medial MNTB for serial image collection. Tissue blocks were scanned using a Quanta field emission gun scanning electron microscope (FEI) or a Merlin scanning electron microscope (Zeiss) and sectioned at a thickness of 60 or $40 \mathrm{~nm}$ (P9). Accuracy of section thickness was estimated by assuming circularity of mitochondria and comparing the diameter of longitudinally oriented organelles with diameters measured in the image plane (Wilke et al., 2013). These values approximated the nominal section thickness (P2, $58.4 \mathrm{~nm}$; P3, $55.3 \mathrm{~nm}$; P4, $56.5 \mathrm{~nm}$; P6, $53.2 \mathrm{~nm}$; P9, $35.9 \mathrm{~nm}$ ). Tissue dimensions and pixel sizes are indicated in Table 1.

Segmentation and three-dimensional reconstruction. Image files were shipped to WVU for analysis. Cells were segmented, reconstructed, and analyzed using the IMOD 3D reconstruction and visualization software (Boulder Laboratory for 3-D Electron Microscopy of Cells, University of Colorado, Boulder). Most reconstructions were completed using either a Velocity D55SQ workstation (Xeon X5677 3.46 GHz quad-core processor, 96 GB RAM, 640 GB solid state drive storage, 2.4 TB 15,000 rpm serial attached Small Computer System Interface storage, Linux Red Hat Enterprise Release 5.7; Pogo Linux), a Dell Precision T7500 desktop computer (Dual Intel Xeon X5687 3.6 GHz quad-core CPUs, 48 GB RAM, 240 GB solid state drive storage, 2.5 TB 15,000 rpm serial attached Small Computer System Interface storage, Windows 7 Professional 64bit operating system; Dell), or a Dell Precision T1500 desktop computer (Intel Core i5-750 2.67 GHz quad-core processor, 16 GB RAM, 600 GB solid state drive, Windows 7 Professional 64-bit operating system; Dell). Each computer was interfaced to an interactive display drawing tablet and pen (Model DTU-2231, Wacom) for manual segmentation of objects within the tissue volume. Many reconstructions were performed on image volume subsets on laptop computers running IMOD and interfaced to a Wacom Bamboo Splash drawing tablet. Neurons were identified within each SBEM dataset and differentiated from glia by ultrastructural criteria (Peters et al., 1991). Cells were omitted from tracing if a portion of the cell body was truncated by the bounds of the 
dataset, or if a sufficient portion of an input extended outside of the data volume to prevent its identification as a distinct input. The nucleus, cell body, and all neural inputs were segmented for 58 cells across tissue samples from P2 to P6 and dendrites were segmented for 51 of these cells. Reduced quantitative analysis of only input number and size was assessed for an additional 61 cells across this age range; inputs were tracked to separate axons and axons were tracked through the image volume. Qualitative determination of a dominant large input was possible for 57 of the 66 cells present in the P9 volume due to the large size of the terminal. For cells at P9 where a dominant large input was not evident (9 of 66), quantitative analysis of apposed surface area (ASA) was performed. A large tracing team (total 28 people) completed the segmentations. We established a ranking process of expert-level and junior-level competency for tracing team members to minimize the two most common types of errors in segmentation: (1) missed cellular features because parts of cellular objects (e.g., cell body, neural input) were overlooked or mistakenly considered not to be connected to an object, or (2) introduction of new features by fusing two different objects resulting from uncertainty in aligning small-caliber structures $(<100 \mathrm{~nm})$ across sections. Expert tracers (initially G.A.S. and B.K.H., who completed a previous serial section EM study of the MNTB; Hoffpauir et al., 2006) were identified by their experience and absence of errors during segmentation. Errors in category 1 were addressed by having expert tracers proof all of the work of junior tracers. Category 2 issues were identified during tracing and were resolved by review with an expert tracer and, if necessary, tracking the questioned object through the image volume to determine whether it was a part of a different cell. All junior tracers were instructed to highlight uncertainties in tracking objects across sections for resolution by expert tracers. A final check was to examine rendered structures for atypical features, such as obtuse branching angles or sudden changes in dimension, and reinspect these structures in the image volume. Consistent absence of these defined errors led to promotion of junior tracers to expert status. To balance efficiency and accuracy, manual segmentation was performed on every third section containing each object; comparisons between traces of every section and every third section yielded a difference of $<5 \%$ in total surface area. ASAs were traced at the contact between each presynaptic input and its postsynaptic partner and meshed using the IMOD meshing tool, creating a two-dimensional sheet-like surface. Surface area calculations were accomplished using the imodinfo command, which calculates the total surface area by summing all of the triangular areas composing the meshed surface (http://bio3d.colorado. $\mathrm{edu} / \mathrm{imod} / \mathrm{doc} / \mathrm{man} / \mathrm{imodinfo}$.html). All binning and ratio calculations were performed using Microsoft Excel (Microsoft) and graphs were generated using Matlab (The MathWorks).

Electroporation and imaging of acute brain slices. Mouse whole-head or brainstem slices (250-350 $\mu \mathrm{m})$ were generated using a Compresstome VF-200 tissue cutter (Precisionary Instruments) in ice-cold oxygenated ACSF. Extracellular solution of ACSF consisted of (in $\mathrm{mM}$ ) the following: $125 \mathrm{NaCl}_{2}, 2.5 \mathrm{KCl}, 1 \mathrm{MgCl}_{2}, 2 \mathrm{CaCl}_{2}, 25$ glucose, $25 \mathrm{NaHCO}_{3}, 1.25$ $\mathrm{NaH}_{2} \mathrm{PO}_{4}, 0.4$ ascorbic acid, 3 myo-inositol, and $2 \mathrm{Na}$-pyruvate, pH 7.3. A total of eight mice aged P3 (7 animals) and P4 (1 animal) were used to generate brainstem tissue slices for these experiments. Following sectioning, slices were allowed to cool to RT before transfer to an in vitro recording chamber, where they were maintained in oxygenated ACSF at $35^{\circ} \mathrm{C}$ (dual in-line heating units, and a heated stage with an RC-27L tissue chamber and TC-344B temperature control module; Warner Instruments) until completion of electroporation labeling (typically $<2 \mathrm{~h}$ ). Constant perfusion of oxygenated ACSF $(2 \mathrm{ml} / \mathrm{min}$ ) was supplied by a Valvelink 8 perfusion system (Automate Scientific). All data collection for imaging or electrophysiological experiments was complete within $6 \mathrm{~h}$ of tissue sectioning.

Focal application of fluorescent markers was accomplished by selective targeting of afferent fiber bundles at the ventral midline and proximal to the MNTB. Afferent fibers and terminals were labeled by electroporation of Alexa fluorescent dyes (5\% in PBS) coupled to dextran (Alexa 488 or 548; Invitrogen). Electroporation pulses of $20-40 \mathrm{~V}$ were delivered in sets of 10 pulses at $16 \mathrm{~Hz}$ through pipettes of 2-3 $\mathrm{M} \Omega$ resistance. Stimulation protocols were created and controlled by pClamp 9.2 software (Molecular Devices) and administered through an S-940/S-910 stimulus isolation system (Dagan). Pipette guidance and differential interference contrast observation of tissue slices was performed with an Axioskop II plus microscope (Zeiss) with a $40 \times(0.75$ numerical aperture) dipping lens.

Image stacks ( $Z$-step size $0.7-1.2 \mu \mathrm{m}$ ) were collected using either a Zeiss LSM510 confocal microscope or custom-built 2P microscope (Yang et al., 2013). Confocal microscopy was performed using a $20 \times$ (0.75 numerical aperture) PLAN NEOFLOUR lens. The $2 \mathrm{P}$ system was comprised of a Verdi-V18 pumped, Mira-HP Ti-Sapphire laser (Coherent) mode-locked at $780 \mathrm{~nm}$, an upright microscope (Moveable Microscope, Sutter Instrument) equipped with a scanner (Cambridge Instruments) and $20 \times$ (1.0 numerical aperture) PLAN APO dipping lens (Olympus). Image acquisition was controlled using ScanImage software (Pologruto et al., 2003) operating on a Matlab platform. Images were converted to TIFF format and imported into Imaris (Bitplane) for viewing and qualitative analysis. Images of the compressed image stacks were imported into Photoshop (Adobe) for highlighting and figure creation.

Calcium imaging and electrophysiology. Data are replotted and reanalyzed from Hoffpauir et al. (2010) and that article should be consulted for detailed experimental methods. Briefly, for minimal stimulation experiments a dual-shaft tungsten microelectrode (FHC) was positioned over trapezoid body afferent fibers at the ventral midline. Tissue visualization for these experiments was performed on the Axioskop II system with constant ACSF perfusion at $35^{\circ} \mathrm{C}$ as described above. Connected cells were identified by evoked calcium signals following loading with Fura2-AM (Invitrogen). Excitation light at 340 and $380 \mathrm{~nm}$ was supplied by rapid filter switching with a Lambda DG-4 system (Sutter Instrument) controlled by HC Image software (Hamamatsu) and images were captured at $25 \mathrm{~Hz}$ with a Hamamatsu C9100-12 EM-CCD camera. Responsive cells were targeted for whole-cell voltage-clamp recording $\left(V_{\text {hold }}=-70 \mathrm{mV}\right)$ using a multiclamp 700A microelectrode amplifier, Digidata 1322A digitizer, and CV-7A headstage controlled by pClamp 9.2 software (Molecular Devices). Data were acquired at a sampling rate of $50 \mathrm{kHz}$ and low-pass filtered at $6 \mathrm{kHz}$. Series resistance compensation was set to at least $70 \%$ for all recordings. Internal recording solution for voltage clamp contained the following (in $\mathrm{mm}$ ): $114 \mathrm{~K}$-gluconate, $26 \mathrm{KCl}$, $2 \mathrm{MgCl}_{2}, 0.1 \mathrm{CaCl}_{2}, 1.1$ EGTA-Na 4,10 HEPES, $5 \mathrm{Na}$-phosphocreatine, and 4 ATP-Mg, $\mathrm{pH}$ 7.3. Trapezoid body stimuli were varied in $2 \mathrm{~V}$ increments from 2 to $40 \mathrm{~V}$. A selected minimal stimulation set was repeated four times in a randomized presentation order to circumvent effects of stimulus order.

Statistical analysis and curve-fitting. The increase in average ASA size between P2 and P6 was assessed using nonparametric tests, since size distributions were skewed toward large values and had increasing variability with age. For these reasons, data were transformed so that SDs were identical and the hypothesis that means increased each day from P2 to P4 was tested. A Jonckheere-Terpstra test was used to assess overall significance and a post hoc test attributed to Hayter-Stone in Hollander and Wolf (1999) was used to assess differences between individual pairs of means. Other statistical analysis used the $t$ test. Values reported in the text are mean \pm SD.

The rate for emergence of dominant, large inputs was determined using the following equation:

$$
y=A\left(1-e^{\frac{-(t-2)}{\tau}}\right)
$$

where $t$ is age, $\tau$ is the time constant, $A(100)$ normalizes the maximum (asymptotic) value to $100 \%$, and $(t-2)$ shifts the beginning value to $\mathrm{P} 2$.

Data for calyx growth were fit to a Boltzmann equation and compared with fits for maturation of action potential (AP) firing phenotype and AP threshold to current injection (Hoffpauir et al., 2010):

$$
Y=\frac{A_{1}-A_{2}}{1+e^{\frac{t-t_{1 / 2}}{k}}}+A_{2}
$$

where $A_{1}$ and $A_{2}$ are the initial and final conditions, respectively, $t$ is age, $t_{1 / 2}$ is the age of half-maturation, and $k$ is the slope factor. 


\section{Results \\ SBEM is a powerful tool to investigate nervous system development}

To quantify growth dynamics of the $\mathrm{CH}$, resolution of cellular ultrastructure was necessary to assay the size and extent of physical contact between nerve terminals and the postsynaptic neuron, verify that terminals contained structural elements of synapses, and exclude frequent axon-somatic contacts in the developing MNTB that lack synaptic machinery (Hoffpauir et al., 2006). Furthermore, although most cells of the MNTB in mice are considered principal cells, a small percentage of neurons may be of a different cell type, and not innervated by CHs (Banks and Smith, 1992). We considered that ultrastructural criteria might be useful to identify nonprincipal cells at young postnatal ages and exclude them for a more accurate analysis of calyx growth dynamics.

Tissue blocks were collected at multiple postnatal time points (Fig. 1A, P2-P4, P6, P9), encompassing salient changes in mouse MNTB innervation (e.g., increases in terminal size, strength of evoked EPSCs, and innervation by multiple inputs) as described in previous studies (Kandler and Friauf, 1993; Hoffpauir et al., 2006, 2010; Rodríguez-Contreras et al., 2008). Minimal stimulation electrophysiological techniques in rat indicated that nearly all MNTB cells (93\%) are monoinnervated by P9 (Bergsman et al., 2004). This dense temporal sampling provided a time series view of neural development, albeit using a different animal at each age, at ultrastructural resolution. We addressed fundamental questions about $\mathrm{CH}$ :MNTB development, such as the number of small inputs preceding calyx growth, the extent of competition during calyx growth, the speed of calyx growth, and the age by which all MNTB cells were contacted by large inputs (Fig. 1A, question marks). High-resolution image stacks, oriented in the coronal plane at all ages, were obtained from the medial portion of the MNTB using SBEM (Fig. 1B), providing a robust and highly detailed dataset for each sampled age. The medial MNTB was sampled to avoid potential regional differences in maturation within this cell group (Rodríguez-Contreras et al., 2008; Ford et al., 2009). Sampled volumes ranged from $\sim 400,000$ to $1,000,000 \mu \mathrm{m}^{3}$ (Table 1). This age range and specified sample region permitted a systematic and dynamic view of calyx and principal cell development amenable to quantitative analysis.

MNTB principal neurons and their synaptic inputs were manually segmented from the image volume. The nucleus, cell body, dendrites, and axon were segmented as distinct objects, as was each somatic input and its associated axon (Fig. 1C). This approach yielded high-resolution three-dimensional representations of neurons and their synaptic inputs across the age range selected for analysis. A representative section through a cell with two large inputs is depicted in Figure $1 C$ [largest input (1) colored blue; second largest input (2) colored green]. We noted that glial processes could intervene between a neural input and the principal neuron and reduce the contact area between cells (Fig. 1C, g, purple structures and open purple arrowheads, respectively). Therefore, the contact between input and somatic membrane was segmented separately and reconstructed for each input to yield the ASA. The ASA is representative of the available space for both current and potential synaptic contacts to form between the growing terminal and the MNTB cell body. ASA size can be measured accurately in these images and was used as the metric for synaptic strength, especially given uncertainty that all postsynaptic densities were resolved. In addition, synaptic strength may not scale linearly with size or density of synaptic structures due to variance in numbers of docked vesicles, vesicle pool size, and density of glutamate receptors. All large terminals (see below) were filled with synaptic vesicles and multiple synapses could be identified within each terminal, consistent with our earlier report using higher-resolution imaging over smaller serial section volumes (Hoffpauir et al., 2006). Functional inputs were identified, then, as having synaptic vesicles clustered at membrane apposition sites (Fig. $1 C, \mathrm{sv})$. In a subset of terminals at P6 $(n=7)$, where smaller pixel dimensions (Table 1) rendered identification of the active zone (AZ) more reliable, $\mathrm{AZ}$ size was linearly related to ASA $\left(R^{2}=0.97\right)$. The ASA, then, was used to distinguish innervation territories of multiple inputs, investigate the prevalence of synaptic competition, and quantify the dynamics of calyx growth.

\section{P2: MNTB cells are contacted by multiple small inputs}

At P2, as has been shown previously in a small tissue sample (Hoffpauir et al., 2006), neurons in the MNTB are packed tightly (Fig. 2A, cells colored gold and numbered) with large areas of cell-cell contact (white arrowheads between cells 1 and 2, 3 and 4). Even in single sections, neurons appear to be extensively covered by glial processes (Fig. $2 A$, purple structures). Consequently, a large portion of the cell membrane is inaccessible for innervation. Somatic neural inputs, identified by collections of synaptic vesicles in regions of directly apposed presynaptic and postsynaptic membrane (Fig. $2 A$, inset), were small (average ASA, $2.38 \pm 2.5 \mu \mathrm{m}^{2} ; n=21$ cells, 204 inputs total; Fig. $2 B$ ). The size distribution revealed many small inputs with few inputs having an ASA $>5 \mu \mathrm{m}^{2}$ ( 25 of 204 inputs, $12.3 \%$; Fig. $2 B$ ). The inputs to each cell are plotted in order of increasing size and linked by lines in Figure 2C. Most cells had between 5 and 12 inputs on the cell body (average, $9.3 \pm 6$ inputs; Fig. $2 C$ ). Three-dimensional reconstructions depict the principal cells of the MNTB at the earliest stage of input formation, with multiple small inputs impinging upon each cell. Most somatic inputs at P2 were en passant in morphology (Fig. 2D,E, most inputs), even though they occurred in branches of axons that passed near the cell body (Fig. 2D, inputs 1 and 8). These latter axons had periodic swellings that were filled with synaptic vesicles and which frequently made synaptic contacts with dendrites of neighboring MNTB principal cells (Fig. 2D, arrowheads show example regions of axon filled with vesicles). One of the largest inputs at this age, termed a protocalyx by Morest (1968) (Fig. 2E, black arrowhead) may have been captured in the earliest stage of expansion over the somatic surface.

We considered that some inputs destined to form calyces may initially contact the dendrites of MNTB cells, as occurs for auditory nerve fiber innervation of bushy cells in the ventral cochlear nucleus (Mattox et al., 1982), and that round vesicle shape is not as reliable an indicator in neonatal animals of excitatory input as it is in adults (Vaughn, 1989). Since large-diameter fibers of the trapezoid body originate from globular bushy cells of the ventral cochlear nucleus and give rise to calyces in the mature brain (Warr, 1972; Spirou et al., 1990; Smith et al., 1991), we identified large-diameter fibers at P2 (average, $1.59 \pm 0.4 \mu \mathrm{m}$ diameter) and mapped several of these fibers and their branches (Fig. $3 A$ ). We discovered that large-diameter axons branched 2-4 times in the image volume, and these branches further branched so extensively that a single fiber may contact over $20 \mathrm{MNTB}$ cells (22.5 \pm $12, n=12$; Fig. $3 A$, center of contacted MNTB cells plotted as green spheres). Conversely, we investigated whether multiple large-diameter axons had branches that converged via somatic and dendritic inputs onto a single MNTB cell (Fig. 3B). We iden- 
A
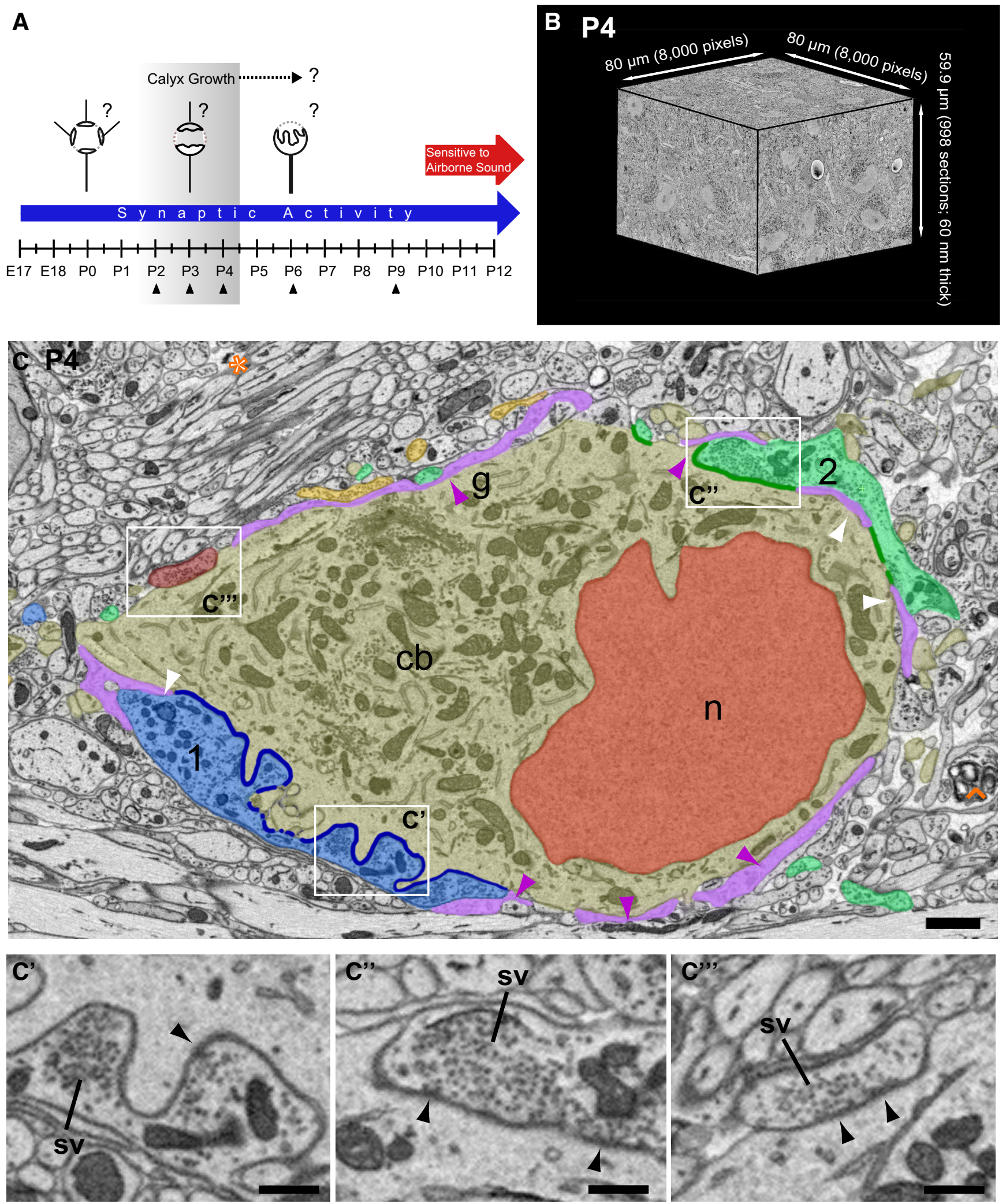

Figure 1. Experimental design and tissue analysis for time series SBEM. A, Calyx growth occurs in context of synaptic activity and precedes ear canal opening (termed sensitivity to airborne sound). Tissue samples taken at P2, $\mathrm{P3}, \mathrm{P4}, \mathrm{P6}$, and $\mathrm{P9}$ to permit assay of exuberant innervation, strengthening, and pruning of a subset of inputs and resolution of monoinnervation (question marks) and dynamics of calyx growth (shaded area, calyx growth $\rightarrow$ ?). B, Representative SBEM volume from P4 animal. (ross-sectioned neurons, glia, and capillaries (white circles with darkened cores) are evident on the block faces. Perspective view alters perceived length of edges. $\boldsymbol{C}$, Portion of single slice from SBEM volume depicted in $\boldsymbol{B}$ reveals cellular details. Objects segmented from volume by tracing cell membranes are colorized for ease of identification in this figure: nucleus (n, red); cell body (cb, gold); largest calyciform input (1, blue); second largest calyciform input (2, green); smaller inputs (burgundy, yellow); glial covering of cell body ( $g$, purple-shaded areas and purple arrowheads) and thin glial incursions between input and cell body (white arrowheads). Yellow input is excluded by glia from contact with soma in this section. Size of inputs quantified as ASA with cell body (input 1, dark blue line; input 2, dark green line), excluding glial incursions. Developing brain contains much open space (orange asterisk) and areas of degeneration (orange caret). Zoomed views of three inputs $\left(\boldsymbol{C}^{\prime}, \mathbf{C}^{\prime \prime}, \mathbf{C}^{\prime \prime}\right)$ show groupings of synaptic vesicles (sv) and active zones (black arrows) where vesicles cluster along the presynaptic membrane. Scale bar: $\boldsymbol{C}^{\prime}, 2 \mu \mathrm{m} ; \boldsymbol{C}^{\prime}-\boldsymbol{C}^{\prime \prime \prime}, 0.5 \mu \mathrm{m}$. 


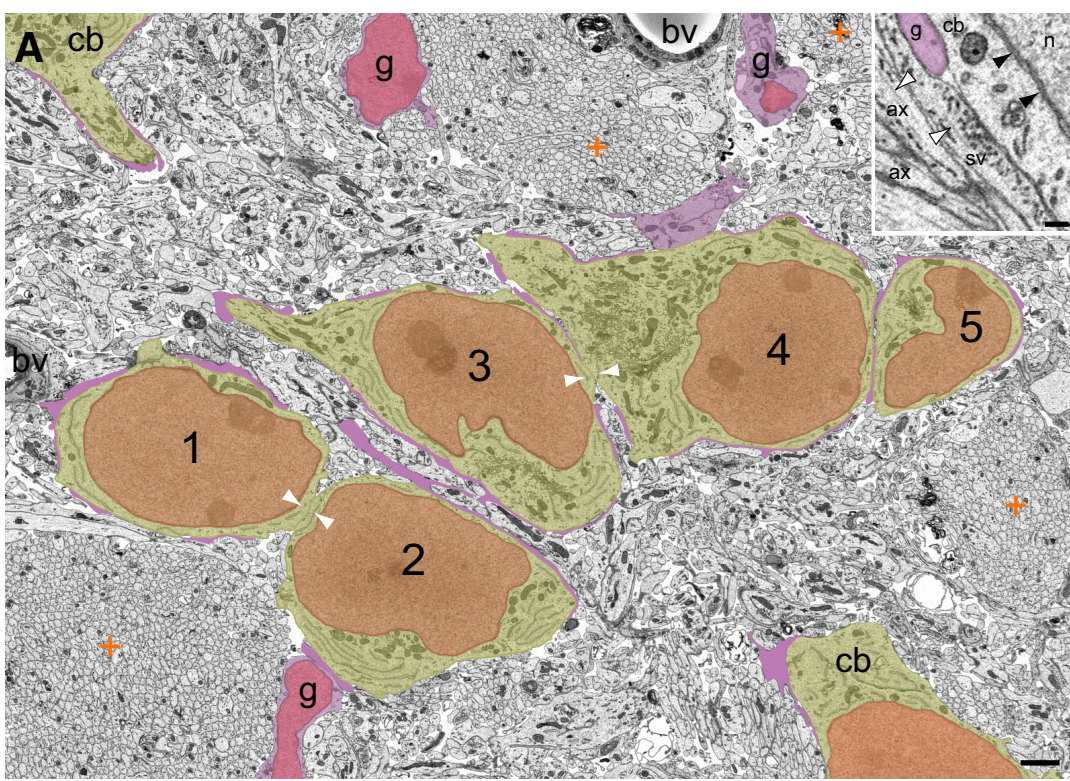

B
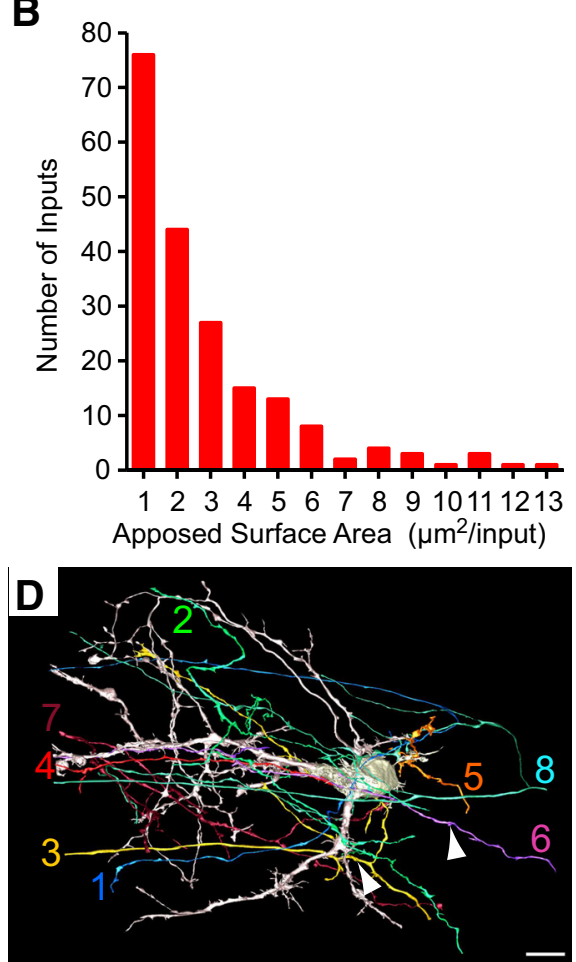

\section{C}

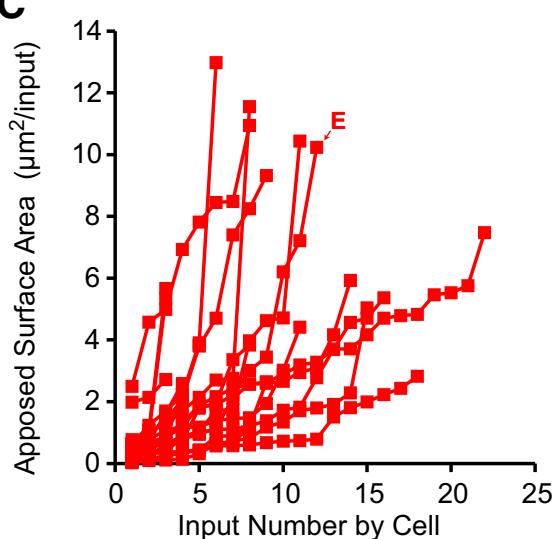

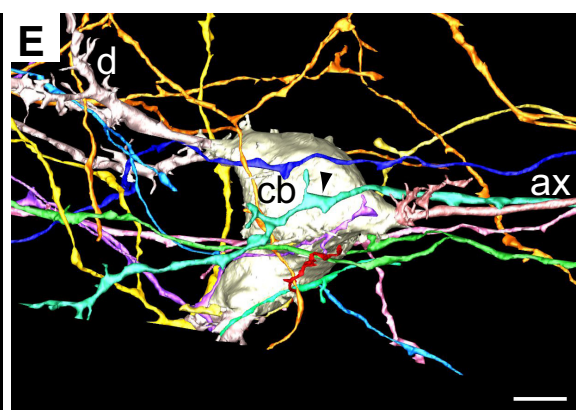

Figure 2. Clustering of cells and quantification of somatic inputs at P2.A, Region of single image at P2 shows cluster of MNTB cells (gold, 1-5) with direct membrane apposition (white arrowheads) and glial covering (purple), which can form thin layers between cells. Glial cells (g), other MNTB cell bodies (cb), and blood vessel (bv) also shown. Large bundles of crosscut cellular processes (orange plus signs) are prominent structures. Inset, Example of small synaptic terminal identified by synaptic vesicles (sv) clustered at apposition with thin region of MNTB cell body cytoplasm (cb) surrounding nucleus ( $n$; black arrowheads indicate double membrane of nuclear envelope). Microtubules (white arrowheads) are evident in axon forming synaptic contact and adjacent axons (ax), which do not contain synaptic vesicles. $\boldsymbol{B}$, Size distribution (ASA) of all inputs ( $n=204$ ) to reconstructed cells (21 of 71 cells in volume), binned at $1 \mu \mathrm{m}^{2}$ increments. $C$, Inputs (red squares) to each cell linked by lines and plotted from smallest to largest. Cell in $\boldsymbol{E}$ is indicated by Eand arrow. $\boldsymbol{D}, 3 \mathrm{D}$ reconstruction of cell with small inputs to cell body (1-8) and showing highly branched dendrites. Several inputs branch from mediolateral-oriented axons $(3,8)$. $\boldsymbol{E}$, Close-up of another MNTB neuron showing cell body (cb), proximal dendrites (d), axon (ax), and inputs to cb. One of the largest inputs at this age makes en passant contact (black arrowhead). Dendrite and axons truncated at bottom by edge of image volume. Scale bars: $A, 2 \mu \mathrm{m}$; A, inset, $0.5 \mu \mathrm{m} ; \boldsymbol{D}, 10 \mu \mathrm{m} ; \boldsymbol{E}, 5 \mu \mathrm{m}$.

tified cells contacted by $\geq 4$ of the 12 large-diameter axons that were reconstructed. The cell in Figure $3 B$ was contacted on its soma by 4 of the 5 large-diameter axons depicted; ASAs for 3 of these 4 somatic inputs are shown in the inset. Of the 71 identifi- able MNTB cells in this image volume (because their cell bodies were entirely contained within the volume), 36 (51\%) were contacted by at least 4 of the 12 reconstructed axons. By extrapolating from these values, 24 large-diameter axons $(2 \times$ 12) would generate $\geq 4$ inputs onto all 71 cells, which is fewer than the estimated 60 axons that will monoinnervate these cells in maturity (assuming 18\% of globular bushy cells generate 2 calyces as in rat; Rodríguez-Contreras et al., 2006). It is likely that axons eventually innervating MNTB cells outside of this population of 71 cells also transiently innervate the cells included in the P2 volume, so we suggest that convergence from at least four separate globular bushy cells onto each MNTB cell is a common occurrence. Large-diameter axons very rarely, if ever, branch medially to the MNTB into two large-diameter axons in rodents (Friauf and Ostwald, 1988; Kandler and Friauf, 1993; Rodríguez-Contreras et al., 2006; Hoffpauir et al., 2010; see below), so these axons represent independent inputs.

\section{P3: initiation of calyx growth}

Principal neurons at P3 displayed less cell-cell contact, allowing for greater contact with nerve terminals than was possible at P2 (Fig. 4A, 3 cells indicated) but still have a substantial investment of glial covering (Fig. $4 A$, purple structures contacting cell bodies). Many inputs were larger than at P2 and generated a much broader distribution and larger average value of ASA $\left(10.7 \pm 35 \mu \mathrm{m}^{2}, n=37\right.$ cells, 298 total inputs; Fig. 4B). The histogram of ASA values was multimodal, reflecting populations of small and larger inputs. The first minimum inflection point of this histogram occurred at $25 \mu \mathrm{m}^{2}$ (Fig. $4 B$, vertical dashed line), which was defined operationally as the threshold for differentiating small inputs from large inputs (Fig. 4B, red and black histogram bars, respectively). The inputs to each cell are plotted in Figure $4 C$ in order of increasing size and linked by lines, as in Figure 2C. Most inputs (92\%) at P3 were small and most cells were contacted only by small inputs [21 of 37 (57\%) cells; Fig. 4C, red symbols in bottom graph; Fig. $4 D$, example cell]. Nearly one-half of cells ( 16 of 37 , $43 \%$ ) had $\geq 1$ large input (Fig. $4 C$, open and closed black symbols in upper graph). Example cells are shown in Figure $4 E-F$; note that in $3 \mathrm{D}$ reconstructions the largest and second-largest inputs are colored blue and green, respectively, independent of the number of large inputs. Of these 16 cells, $8(50 \%)$ had at least two large inputs indicative of competition among growing calyces. One of these cells had three large 
inputs (Fig. 4C, asterisk). Considering that some cells with a single large input (Fig. 4E) may have already proceeded through a phase of competition, we considered $50 \%$ to be a minimum estimate of the fraction of MNTB neurons competed for by multiple large terminals with the potential to form calyces (termed calycigenic). Rotated views of a single MNTB neuron illustrate two large inputs (Fig. $\left.4 F, F^{\prime}\right)$.

We performed a more refined analysis of competition in an attempt to distinguish cells in which one large input has become the dominant input. For cells having at $\geq 1$ large input, we calculated the ratio of the two largest inputs onto each cell. A ratio near 1 indicates inputs of similar size and suggests an active competitive process. The distribution of these ratios showed a grouping of cells ( 9 of 15 cells, $60 \%$ ) with an ASA ratio of $\leq 5$. Based upon this metric, we defined this group of cells to be contacted by actively competing inputs (Fig. 4B', open histograms; Fig. 4C, same cells plotted as open diamonds). We then defined ASA ratios $>5$ ( 6 of 15 cells, $40 \%)$ to indicate a dominant large input (Fig. 4B', solid black histogram; Fig. 4C, solid black circles) and considered the inputs to these cells not to be undergoing active competition. This quantification distinguished three categories of MNTB neurons: (1) those with only small inputs likely poised to begin growth, (2) those with actively competing inputs, and (3) those with a dominant large input. Cells in Groups 1 or 2 tended to have a greater number of inputs than those in Group 3 $(8.7 \pm 4$ inputs for Groups 1 and 2 vs $5.7 \pm 3$ inputs for Group 3, $p<0.00001$, Student's $t$ test on pooled data P2-P6). This situation may be a consequence of regression of some small inputs as another subset of small inputs become large.

$3 \mathrm{D}$ reconstructions demonstrate that these three groups of cells reflect different stages of calyx growth. Axons that gave rise to small inputs onto MNTB cell somata often had an en passant morphology and larger axonal swellings nearby that were filled with synaptic vesicles (Fig. $4 D$, white arrowheads), as at P2. Small inputs could branch from large terminals onto adjacent cells (Fig. $4 D$, input 5), can be functional (Rodríguez-Contreras et al., 2008), and may persist into adulthood (Kuwabara et al., 1991). The largest calycigenic input, whether defined as actively competing or a dominant input, typically enlarged from the base of the axon over the somatic surface with sinuous branches radiating into the extracellular space (Fig. $4 E, F, F$, blue and green). Note that for one of the MNTB cells with competing inputs, both inputs were similar in size and among the largest of this group (Fig. 4C, F, symbols enclosed by ellipsoid; Fig. 4F, F', 3D views). The largest inputs $\left(>200 \mu \mathrm{m}^{2}\right)$, however, were from the dominant large input group (closed black circles), suggesting that competition is resolved before the final stages of calyx growth (Fig. 4C).
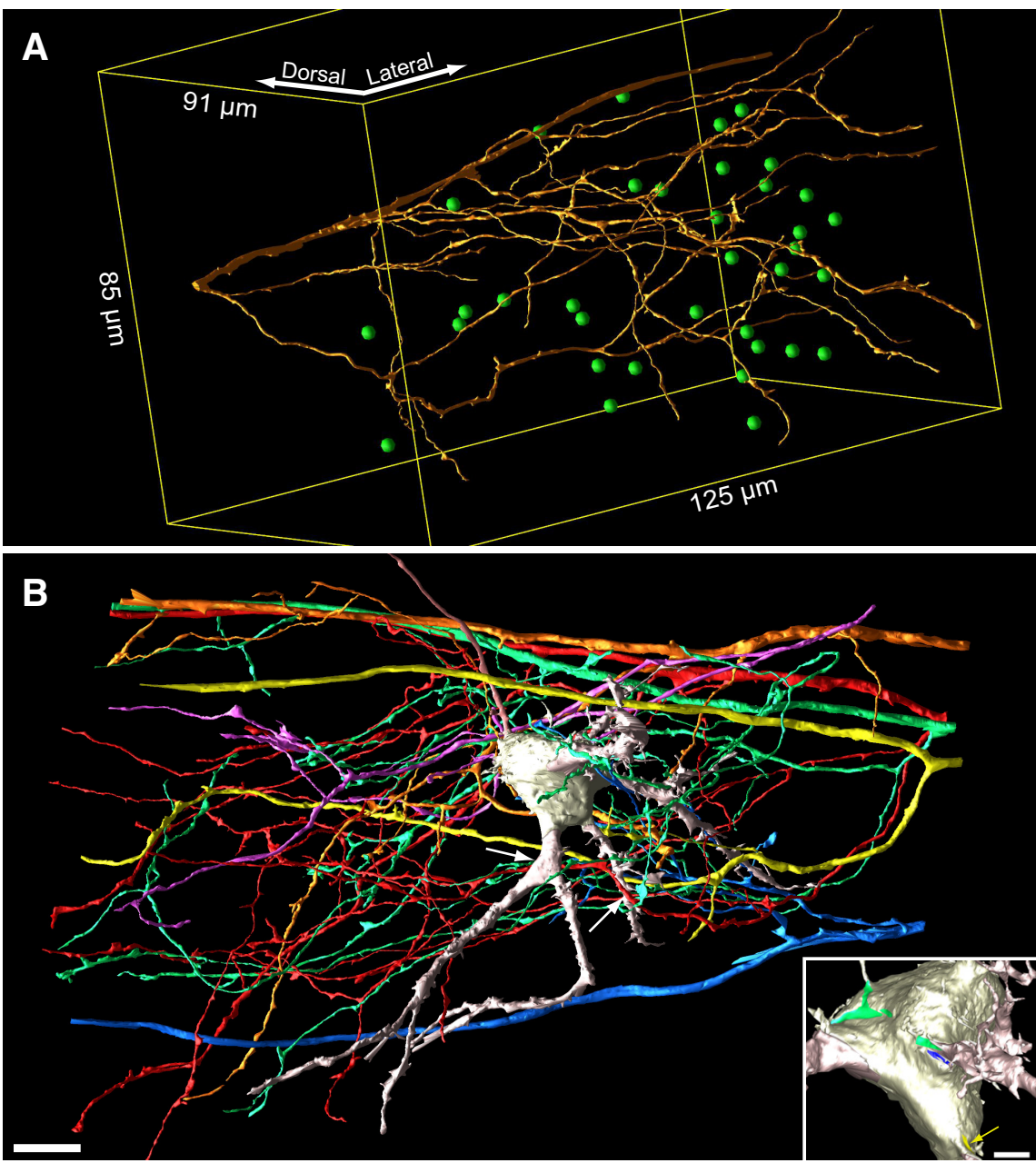

Figure 3. Exuberant innervation of MNTB at P2. A, Reconstruction of single large-diameter axon oriented mediolaterally in image volume. Green spheres indicate center of MNTB cells (35 of 71 cells in volume) with synaptic contact from this axon onto a trapezoid body axons on dendrites (white arrows; left arrow indicates contact on opposite side of dendrite) or cell body [inset, green, blue, and yellow (arrow highlights ASA); fourth ASA not shown] is shown. Contacts occurred via branches from parent axon. Scale bars: $\boldsymbol{B}, 10 \mu \mathrm{m} ; \boldsymbol{B}$, inset, $2.5 \mu \mathrm{m}$.

\section{P4: rapid calyx growth onto all postsynaptic cells}

Principal cells continue to enlarge and maintain their separation from one another between P3 and P4 (Fig. 1C, single P4 cell). Analysis of input size and distribution was performed for $\mathrm{P} 4$ as at earlier ages. The first minimum inflection point in the histogram of input sizes occurred at $25 \mu \mathrm{m}^{2}$ (Fig. 5A, dashed line), which defined, as at P3, the distinction between small (red) and large (black) terminals. Rapid growth of calycigenic terminals over this $24 \mathrm{~h}$ period led to a large increase of average ASA to $60.6 \pm 108$ $\mu \mathrm{m}^{2}$ ( $n=18$ cells, 83 total inputs). All cells at P4 were contacted by at least one large input and most cells (16 of 18) had at least one input $>100 \mu \mathrm{m}^{2}$ in size. The histogram of ASA ratios revealed a break at a value of five, as at P3, to distinguish cells with actively competing from those with a dominant large input. There was an increase over P3 in the fraction of cells having a dominant large input ( 12 of 18 cells, $67 \%$ vs $40 \%$ at P3; Fig. 5A'). This change in innervation profile suggests that a subset of small inputs at P3 grew quickly and competing inputs detected at P3 likely resolved their competition quickly within the $24 \mathrm{~h}$ developmental period between P3 and P4. Several features of innervation were similar to P3. Most cells had one or two large inputs, but two cells had three large inputs (Fig. 4B, C and F; Fig. 4C,F, 3D reconstructions). On 


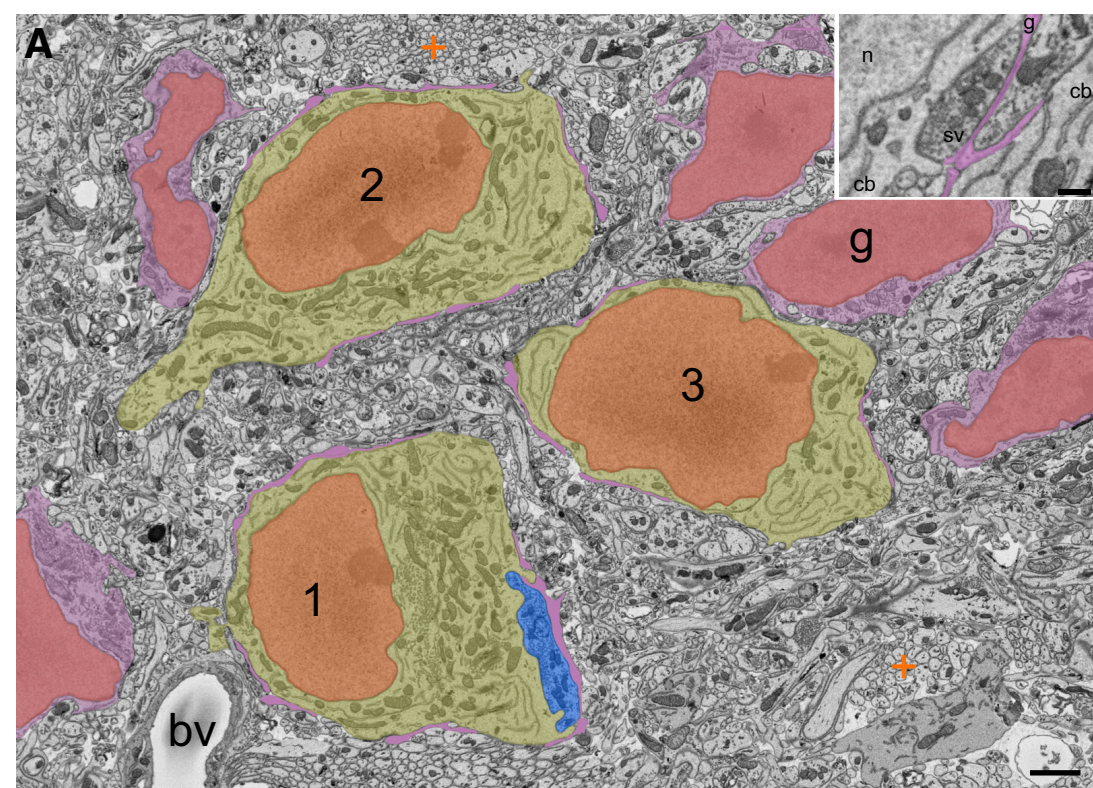

B
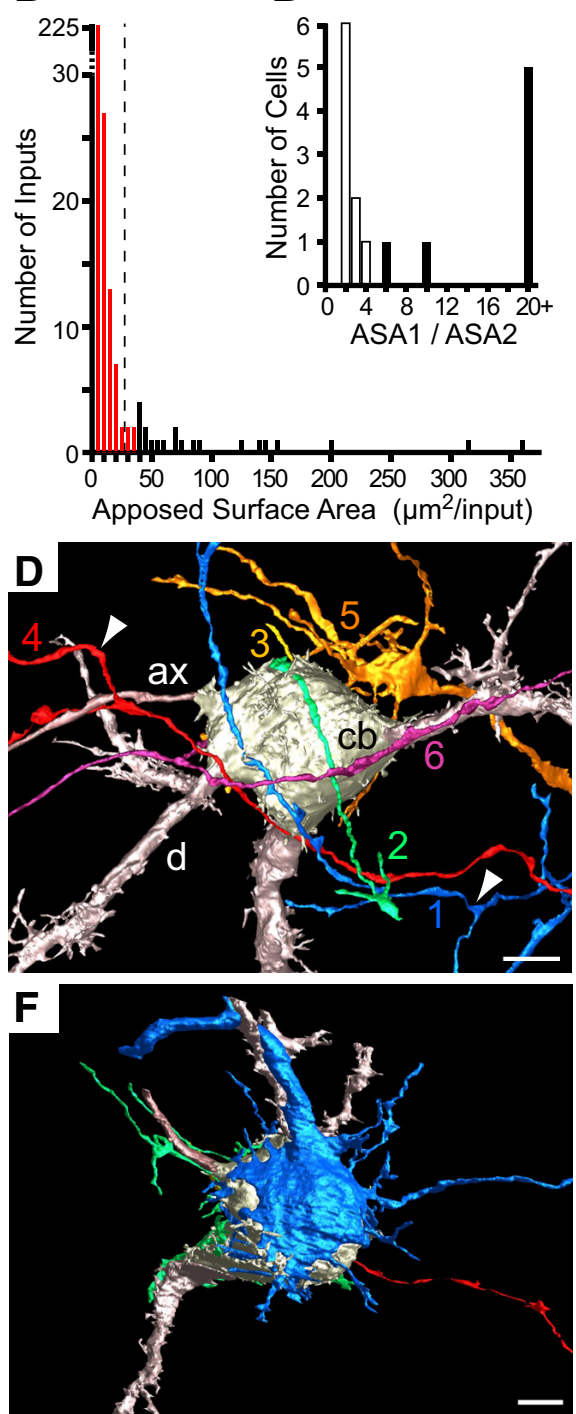

C
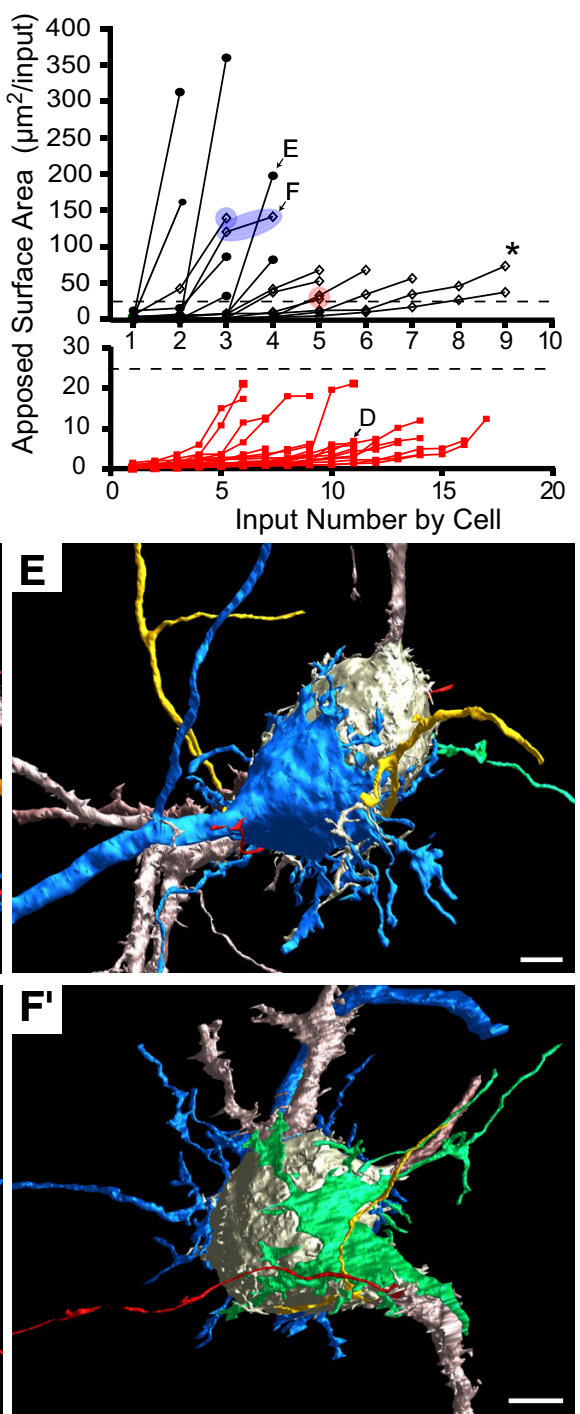

Figure 4. Separation of cells and beginning of rapid nerve terminal growth at P3. $\boldsymbol{A}$, Region of single image showing small field of cells (1-3) with small inputs and less cell-cell contact than at P2, yet retaining significant coverage of cell body surface by glia (purple). A large input (blue) contacts cell 1. Color scheme same as Figure 2. Crosscut cellular processes (orange plus signs) one cell (Fig. $4 B, F$ ) these three inputs were considered to be in active competition. A single cell could have both competing inputs among the largest of all competing inputs (Fig. 5B, symbols shaded by blue ellipsoid; Fig. $5 E$ ). The largest inputs $\left(>260 \mu \mathrm{m}^{2}\right)$ were the dominant inputs on their respective cells (Fig. $5 B-D)$. The presence of some cells at $\mathrm{P} 3$ without large inputs and all cells at P4 with large inputs but a wide range of sizes (Fig. 5B) supports the idea that initiation of calyx formation within a specified region of the MNTB is relatively well synchronized within a $\sim 24 \mathrm{~h}$ period.

\section{P6: increased numbers of} monoinnervated cells

At P6, a larger volume of the medial portion of the MNTB was captured than at $\mathrm{P} 3$, yet it contained a similar number of cells (43 cells), due in part to their wider spacing (Fig. 6A). The input size histogram revealed a minimum inflection point of $35 \mu \mathrm{m}^{2}$, similar to $\mathrm{P} 3$ and $\mathrm{P} 4$, to distinguish small from large inputs (Fig. 6B). Similar to $\mathrm{P} 4$, all but one cell at P6 (42 of 43) had at least one large input. Some cells had more small inputs than at P4, so the average ASA decreased to $42.6 \pm 105 \mu \mathrm{m}^{2}$ ( $n=43$ cells, 306 total inputs). The histogram of input size ratios was divided into values $>5$ or $<5$, as at P3 and P4, defining cells with actively competing inputs $(<5)$ or a dominant large input $(>5)$ (Fig. 6B'). The fraction of cells

indicated as in Figure 2. Inset, Inputs to two adjacent cell bodies (cb) identified by synaptic vesicles (sv) and mitochondria and covered by glial process ( $g$, purple). $B$, Size distribution (ASA) of all inputs $(n=298)$ onto reconstructed cells (37 of 37 cells in volume), binned at $5 \mu \mathrm{m}^{2}$. Local minimum at $25 \mu \mathrm{m}^{2}$ (vertical dashed line) is operational distinction between small (red) and large inputs (black). $\boldsymbol{B}^{\prime}$, Inputs to cells with at least one large input (16 of 37 cells) were analyzed for relative size of two largest inputs (size ratio: ASA1/ASA2). Cells with ASA1/ ASA2 $>5$ ( 7 of 16 cells, closed histogram bars) formed a distinct population from those with smaller size ratios (9 of 16 cells, open black bars). C, Inputs (closed black circles, open black diamonds, red squares) to each cell linked by lines and plotted from smallest to largest. Cells had one (e.g., open black diamond inside blue or red circle), mostly two or three (asterisk) large inputs and both inputs could exceed $100 \mu \mathrm{m}^{2}$ (blue ellipsoid, F). Cells with only small inputs (red) graphed separately for clarity. D, 3D rendering of representative cell contacted by only small inputs. Input 5 is branched from a larger nerve terminal growing on an adjacent cell body. Sizes of inputs to this cell shown in C and marked D. Only largest 6 of 11 inputs shown for clarity. $\boldsymbol{E}, 3 \mathrm{D}$ rendering of representative cell with a dominant large input (blue). Sizes of inputs to this cell shown in $\mathbf{C}$ and marked E. $\boldsymbol{F}, \boldsymbol{F}^{\prime}, 3 \mathrm{D}$ rendering of cell showing largest (blue) and second largest (green, rotated view of same cell) inputs, both of which were $>100 \mu \mathrm{m}^{2}$. Sizes of inputs to this cell shown in Cand marked F. cb, Cell body; d, dendrite; ax, axon. Scale bars: $\boldsymbol{A}, 2 \mu \mathrm{m} ; \boldsymbol{A}$, inset, $0.5 \mu \mathrm{m} ; \boldsymbol{D}-\boldsymbol{F}^{\prime}, 5 \mu \mathrm{m}$. 
with a dominant large input increased slightly to $70 \%$ (32 of 43 ) from $67 \%$ at $\mathrm{P} 4$. Many cells at P6 were contacted by a clearly defined immature calyx $\left(>250 \mu \mathrm{m}^{2}, 19\right.$ of 43 cells, 44\%), which spread over much of the MNTB cell body (Fig. 6D, 3D rendering; Fig. $6 C, D)$. Of the cells with large inputs, only two cells had three large inputs (Fig. $6 C$, asterisks) and these had size ratios $<5$, indicative of active competition. A single cell could have both competing inputs among the largest of all competing inputs as at $\mathrm{P} 3$ and P4 (Fig. 6C, symbols shaded by blue ellipsoid; Fig. 6E). Also like P3 and P4, the largest inputs were dominant inputs (Fig. 6C). Six MNTB cells with actively competing inputs did not have any input $>100$ $\mu \mathrm{m}^{2}$ and one MNTB cell had only small inputs. These cells, and one additional cell that was classified as nonprincipal due to its small size, deeply invaginated nucleus, and limited cytoplasmic volume (data not shown), were located among the most medial members of the cell group.

\section{P9: monoinnervation established on} nearly all principal cells

Since not all MNTB cells at P6 had a dominant large input, we analyzed an image volume from P9. This image volume was larger than at earlier ages (Table 1) and contained 66 neurons. Most cells (58 of 66) had a dominant large input that could be identified qualitatively. A small percentage of cells ( 8 of 66) appeared to have multiple smaller inputs. The ASAs for these inputs were quantified, indicating that seven of eight cells had at least one input defined as a large input $\left(>25 \mu \mathrm{m}^{2}\right)$, but all of these large inputs were $<100$ $\mu \mathrm{m}^{2}$. The input size ratio for these seven cells was $<5$, indicating that a dominant input had not been resolved. The cells without a dominant large input clustered at the medial edge of the MNTB, but appeared similar morphologically to other MNTB principal cells. Thus, competition had resolved on all MNTB neurons except those contained in this cell cluster.
A

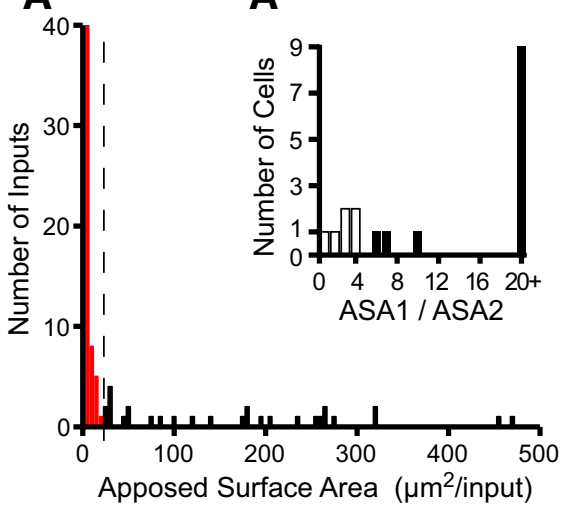

c
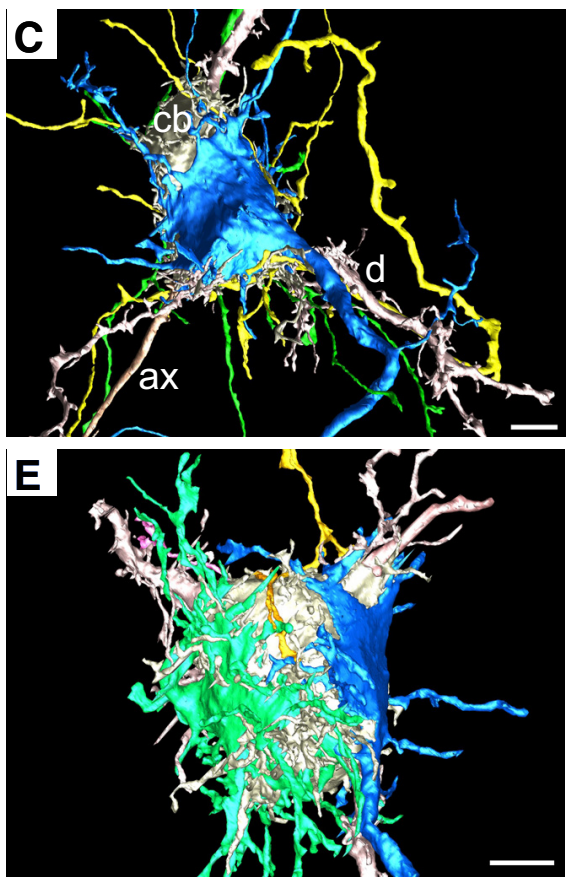

B

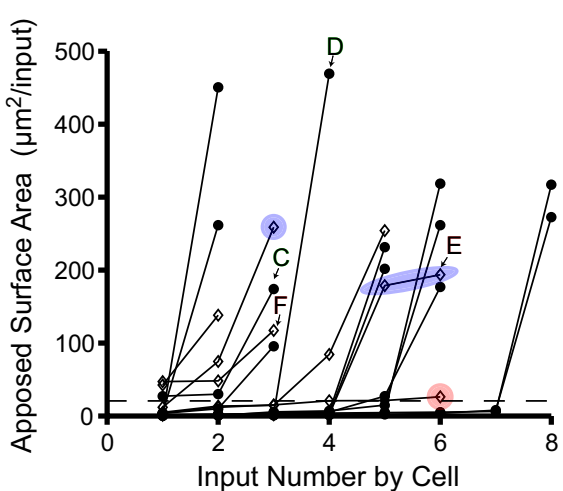

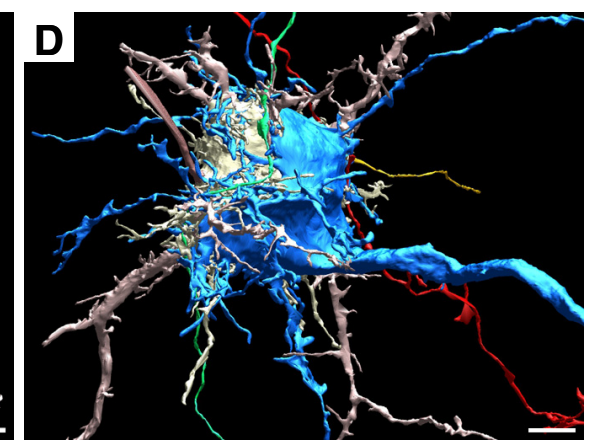

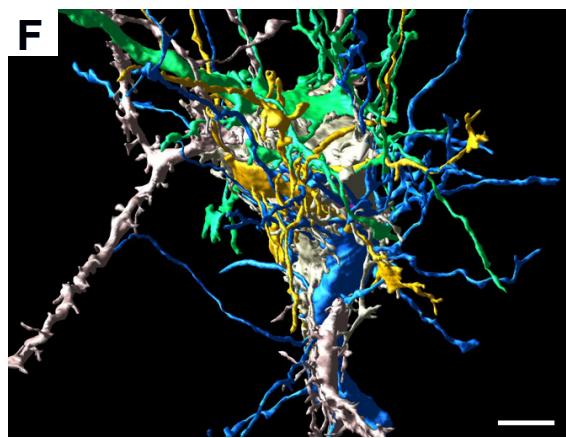

Figure 5. All cells contacted by large terminals at P4. $A$, Size distribution (ASA) of all inputs $(n=83)$ onto reconstructed cells (18 of 18 cells in volume), binned at $5 \mu \mathrm{m}^{2}$. Local minimum at $25 \mu \mathrm{m}^{2}$ (vertical dashed line) distinguishes small (red) and large inputs (black). $A^{\prime}$, Inputs to cells with at least one large input (18 of 18 cells) were analyzed for their size ratio (ASA1/ASA2). Cells with size ratio $>5$ ( 12 of 18 cells; $\boldsymbol{B}$, solid black histogram bars and solid black circles) formed a distinct population from those with smaller size ratios ( 6 of 18 cells; $\boldsymbol{B}$, open black bars and open black diamonds). $\boldsymbol{B}$, Inputs (closed black circles, open black diamonds) to each cell linked by lines and plotted from smallest to largest. Largest inputs $\left(>260 \mu \mathrm{m}^{2}\right)$ were always dominant inputs (size ratio, $>5$ ). Cells with actively competing inputs (size ratio, $<5$ ) had one (e.g., open black diamond in red circle), mostly two (e.g., open black diamond in blue circle), or three (F) large inputs. Two competing inputs could each exceed $150 \mu \mathrm{m}^{2}$ (blue ellipsoid, E). C, Cell with a dominant large input (blue; $\boldsymbol{B}$, C indicates sizes of inputs to this cell). $\boldsymbol{D}$, Cell with largest input (blue; $\boldsymbol{B}, \boldsymbol{D}$ indicates sizes of inputs to this cell). $\boldsymbol{E}$, (ell with two large competing inputs (blue, green; $\boldsymbol{B}, \boldsymbol{E}$ indicates sizes of inputs to this cell). Two smallest inputs to the cell were omitted from the image for clarity. $\boldsymbol{F}$, Cell with three large competing inputs (blue, green, yellow; $\boldsymbol{B}, \boldsymbol{F}$ indicates sizes of inputs to this cell). cb, (ell body; d, dendrite; ax, axon. Scale bars, $5 \mu \mathrm{m}$.

\section{Tracing large inputs to their axons of origin}

A subpopulation of globular bushy cells branch distant from their terminals and give rise to two calyces (instead of 1), each onto nearby MNTB cells (cat: Spirou et al., 1990; Smith et al., 1991; rodent and bat: Kuwabara et al., 1991; estimated 18\% in rat: Rodríguez-Contreras et al., 2006). In rare instances in rat, a single axon could branch near its target (as close as $15 \mu \mathrm{m}$ ) and appear to deliver two large terminals onto the same cell (RodríguezContreras et al., 2006). Since we studied the medial MNTB, many axons were traceable within the SBEM volume to distinct parent axons in the trapezoid body fiber fascicles. Branching of inputs near their targets was captured except for cells at the borders of our image volume. Although branching of trapezoid body axons outside of the MNTB occurs rarely if at all in rodents (Friauf and Ostwald, 1988; Kuwabara et al., 1991; Rodríguez-Contreras et al., 2006), we considered that some competing inputs onto MNTB cells might originate from the same parent axon due to branching outside of the image volume. To address this issue, we electroporated small numbers of axons in mouse brain slices at P3 and P4 with Alexa dyes (Rodríguez-Contreras et al., 2008; Hoffpauir et al., 2010) and imaged their trajectories within and emerging from fiber bundles in the trapezoid body using confocal or two-photon microscopy (Fig. 7). Axons diverged separately from each small electroporation site and were distinguishable in the trapezoid 


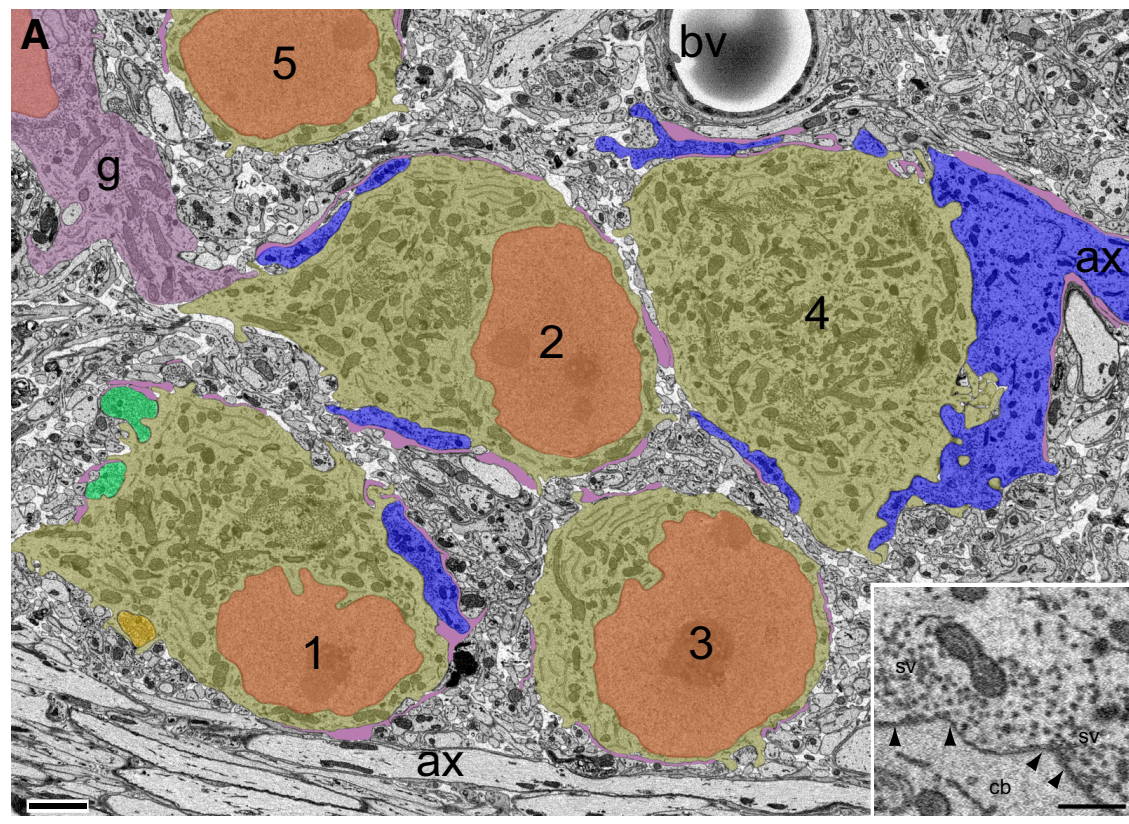

B
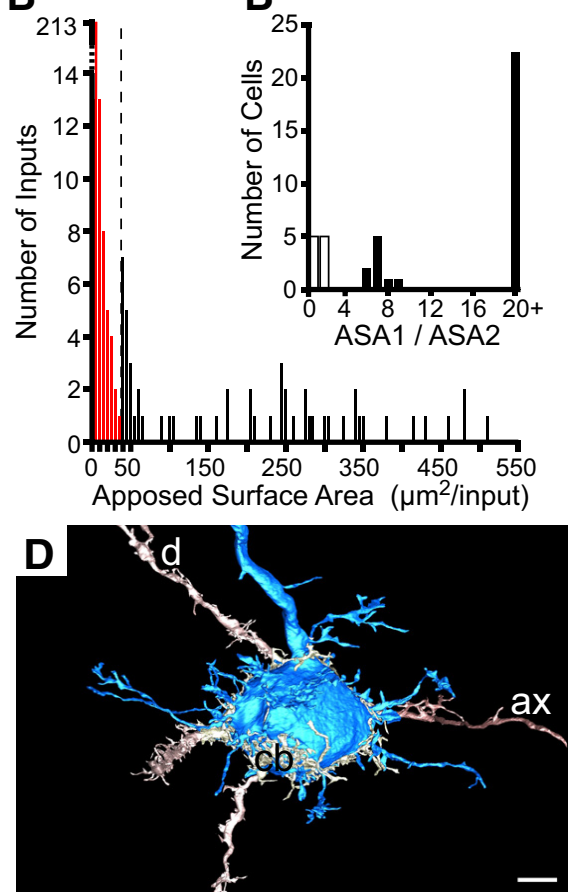

c
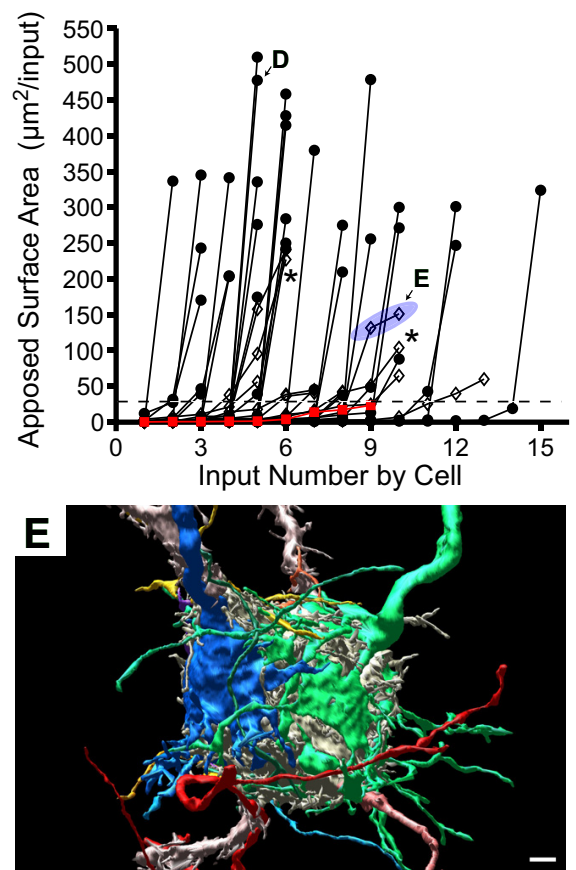

Figure 6. Continued growth and competition at P6. $A$, Region of single image showing small field of neurons with dominant large (cells 2-5; large inputs to cells 3 and 5 not captured in this section) and actively competing inputs ( 3 inputs shown onto cell 1) and a glial (g) cell body. Axon forming calyx onto cell 4 enters at right edge of image. Glial laminae (purple) cover portions of cell body but also the nonsynaptic surface of calyces and calycigenic inputs. Color scheme same as Figure $4 A$. Fiber fascicle traverses in mediolateral direction at bottom of image. $\boldsymbol{A}$, Inset, Terminals contain visible active zones defined by synaptic vesicles (sv) clustered along the presynaptic membrane (black arrowheads). $\boldsymbol{B}$, Size distribution (ASA) of all inputs $(n=306)$ onto reconstructed cells (43 of 43 cells in volume), binned at $5 \mu \mathrm{m}^{2}$ increments. Local minimum at $35 \mu \mathrm{m}^{2}$ (vertical dashed line) distinguishes small (red) and large inputs (black) that potentially form the single calyceal input. $\boldsymbol{B}^{\prime}$, Inputs to cells with at least one large input ( 42 of 43 cells) were analyzed for size ratio (ASA1/ASA2). Cells with size ratio $>5$ ( 32 cells, solid black histogram bars) formed a distinct population from those with smaller size ratios (10 cells, open black bars). C, Inputs (solid black circles, open black diamonds, red squares) to each cell linked by lines and plotted from smallest to largest. Largest inputs ( $\left.>250 \mu \mathrm{m}^{2}\right)$ were always dominant inputs (size ratio, $>5$ ). Cells with actively competing inputs (size ratio, $<5$ ) had two or three (asterisks) large inputs. Two competing inputs could each exceed $125 \mu \mathrm{m}^{2}$ (blue ellipsoid, E). D, Cell with a dominant large input (blue; C, D indicates sizes of inputs to this cell). Smaller inputs omitted for clarity. $\boldsymbol{E}$, Cell with two large competing inputs (blue, green; $\boldsymbol{C}$, E indicates sizes of inputs to this cell). Most smaller inputs omitted for clarity. cb, Cell body; d, dendrite; ax, axon; bv, blood vessel. Scale bars: $\boldsymbol{A}, 2 \mu \mathrm{m}$; $\boldsymbol{A}$, inset, $0.5 \mu \mathrm{m} ; \boldsymbol{D}, 5 \mu \mathrm{m} ; \boldsymbol{E}, 2 \mu \mathrm{m}$. body (data not shown) before entering the fields of view depicted in this figure. Our goal was to label a small enough number of axons in each preparation to evaluate whether branches of single axons converged into the same vicinity via large nerve endings. Only 1 of 20 axons studied in this fashion exhibited the potential for such convergence (Fig. 7A, axon highlighted in yellow and putative terminals by white arrows). For this axon, the nerve terminals were $\sim 5 \mu \mathrm{m}$ apart, but it was difficult to assess whether they contacted the same cell. An angled view from the image stack suggested that the inputs contacted different postsynaptic structures due to curvature of the larger terminal (Fig. 7A, inset, asterisks). An example of more typical branching patterns and convergence are shown in Figure $7 B$. One axon is highlighted in yellow and expands into a single large terminal. Another labeled axon also ends in a large terminal, possibly onto the same but more likely onto a neighboring cell body (Fig. 7B, 2). A third axon (Fig. 7B, 3) delivers a large terminal that in turn extends long, thin processes. These data confirm that the incidence of single axons that branch at distant locations and converge onto single MNTB cells via large terminals is very rare and that our estimates of synaptic competition reflect true convergence of neuronal projections.

\section{Dynamics of calyx growth and}

synchronization with

\section{postsynaptic maturation}

Emergence of a dominant, large input

Figure $8 A$ shows a histogram summary of the distribution of MNTB cells across age based upon categorization of their inputs: (1) cells with only small inputs (red), (2) cells with actively competing inputs (open black, ASA ratio <5), and (3) cells with a dominant large input (solid black, ASA ratio $>5$ ). The growth of large inputs onto MNTB cells is a rapid and well synchronized process, as indicated by the elimination (with 1 exception at P6 and P9) of cells with only small inputs between P2 and $\mathrm{P} 4$, and a significant increase in the percentage of cells with a dominant, large input from P3 to P4. These data also permitted quantification of the rate at which a single input emerged as a dominant input and were fit to a single exponential growth curve with $\tau=2.7 \mathrm{~d}$ (Fig. $8 B$ ).

Rate of calyx growth

To further explore the growth dynamics of this system, averages of the largest in- 

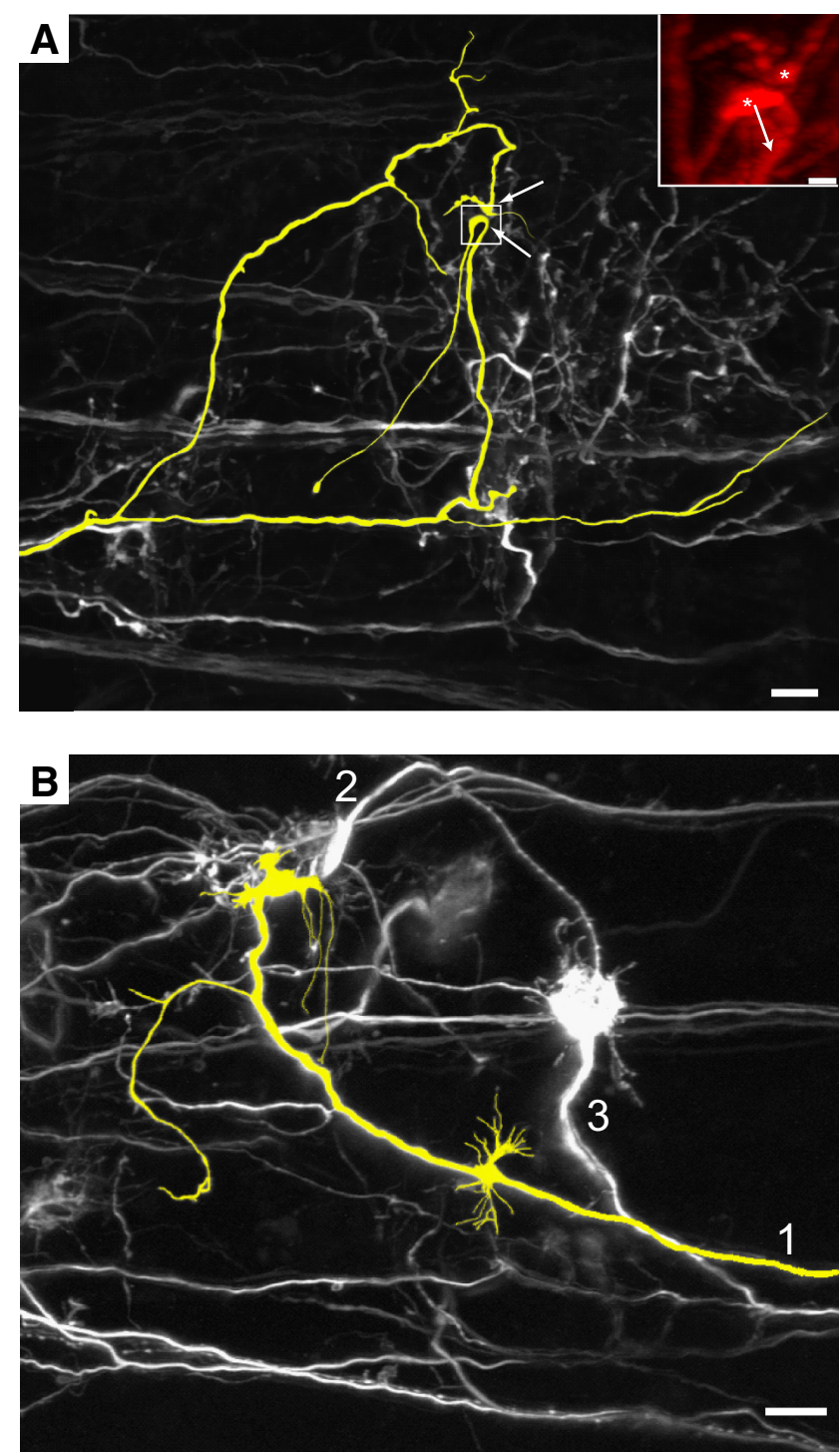

Figure 7. Branches of parent axon do not converge onto the same MNTB cell. $A$, Subset of axons electroporated with Alexa Fluor 488 dye and imaged using two-photon microscopy in P3 animal. Images in both panels are of the collapsed image stack. Only example of axon and branches that terminate near each other (colorized yellow; white arrows indicate terminals). Inset, Close-up of boxed region viewed at angle to demonstrate curvature of large ending (arrow) away from smaller ending (both indicated with asterisks), likely indicating innervation of different postsynaptic structures. $\boldsymbol{B}$, Typical pattern of branching and innervation where axon did not branch at medial locations (area not shown to right of $\boldsymbol{B}$ ) and branches terminate in distinct regions in the MNTB. Axons 1 and 2 terminate via large endings near each other (P4 animal). Scale bars: $\boldsymbol{A}, \boldsymbol{B}, 20 \mu \mathrm{m} ; \boldsymbol{A}$, inset, $5 \mu \mathrm{m}$.

puts onto each cell body at ages P2-P6 were used to generate a growth curve for the populations of sampled cells (Fig. 8C). A Boltzmann fit to the data revealed a half-maximal age $\left(t_{1 / 2}\right)$ of $3.5 \mathrm{~d}$ at a calyx size of $145 \mu \mathrm{m}^{2}$. The maximum growth rate (Fig. $8 C$, dashed curve) at $t_{1 / 2}$ was $207 \mu \mathrm{m}^{2}$ per day. Note that this description of population growth dynamics may underestimate the growth rate of individual calyces. Additionally, ASA was compared across ages using nonparametric statistical methods (see Materials and Methods). The daily increase in mean size from P2 to $\mathrm{P} 4$ was highly significant $(Z=6.64, p<0.0001$, nonparametric Jonckheere-Terpstra test, see Materials and Methods). In follow-up individual comparisons, the mean for P2 was significantly smaller than P3 $(p<0.0001)$, which in turn was signifi- cantly smaller than P4 $(p=0.0003)$. Previously it was demonstrated that maturation of MNTB cells parallels calyx growth (Hoffpauir et al., 2010; Rusu and Borst, 2011), although the population dynamics of calyx growth could only be estimated from physiological measures and serial section EM at the single time point of P4 (Hoffpauir et al., 2006). Boltzmann fits to physiological data from Hoffpauir et al. (2010) are replotted with anatomical measures of calyx growth in Figure $8 D$. Both the transition from tonic to phasic firing and the increase in AP current threshold begin $\sim 1 \mathrm{~d}$ earlier than growth of calycigenic terminals. The half-maximal times for percentage phasic cells $\left(t_{1 / 2}=\right.$ $3.5 \mathrm{~d}$ ) is identical to calyx growth and the value for increase in AP current threshold is $<1 \mathrm{~d}$ delayed $\left(t_{1 / 2}=4.4 \mathrm{~d}\right)$.

\section{Correspondence between electrophysiological and anatomical} counting methods

Because these ultrastructural data reveal all inputs onto the MNTB cell, we used them as a template to similarly analyze physiological measures of input number and synaptic current amplitude from Hoffpauir et al. (2010). Since minimal stimulation techniques revealed fewer inputs per cell and there were fewer inputs measured physiologically per age, we combined ages $\mathrm{P} 2-\mathrm{P} 4$ to capture the transition in input size and generate a histogram of evoked EPSC amplitudes. This histogram had a noticeable gap at $500 \mathrm{pA}$, which we defined as differentiating large from small inputs (Fig. 9A). This value was intermediate between threshold values ( $\sim 400 \mathrm{pA}-1 \mathrm{nA}$ adjusted for holding potential) for calyceal inputs used in studies of older animals, which have fewer small inputs (Forsythe and Barnes-Davies, 1993; Futai et al., 2001; Bergsman et al., 2004). For cells with at $\geq 1$ large input, we next calculated the ratio of EPSCs separately for each age. At P3, 31\% (5 of 16) of cells had $\geq 1$ large input, and at $\mathrm{P} 4$ this value increased to $78 \%$ (18 of 23 ). The fraction of cells with $\geq 1$ large input was slightly less than values obtained using SBEM (41\% at P3, 100\% at P4), consistent with the notion that some inputs are cut during brain slice preparation or that some inputs have similar thresholds, resulting in underestimates of cells having large inputs. We next calculated the input size ratio, as with anatomical data, as a metric for cells that had an established dominant input. At P3 and P4, the input size histograms had a break at values of $\geq 4$, similar to anatomical data, to differentiate cells with actively competing inputs from cells with a dominant input (Fig. 9A', A'). At P3, 2 of 16 (12.5\%) cells had a dominant large input and at P4 this fraction increased to 12 of $23(52 \%)$. As with the other physiological parameters, these values were less than anatomical measures (Fig. 9B).

\section{Innervation territories of competing inputs are segregated}

As calyx-forming inputs grow, they establish new synapses with the MNTB neuron. At the NMJ, postsynaptic receptor sites are mapped onto the muscle surface and are relatively invariant in position although they grow in size (Balice-Gordon and Lichtman, 1990). Also, innervation of receptor loci can be traded between competing inputs (Walsh and Lichtman, 2003). For CF:PC innervation, small inputs are intermingled on the cell body before the eventual "winning" input extends over the dendritic end of the cell body in the capuchon stage of terminal development (Sugihara, 2005; Hashimoto et al., 2009). We investigated locations of competing inputs on the MNTB somatic surface to determine whether competing inputs were interdigitated, which would indicate that they vied for the same postsynaptic territory, or whether they were segregated as eventually occurs at the CF: PC. The ASA and glial incursions for all actively competing in- 

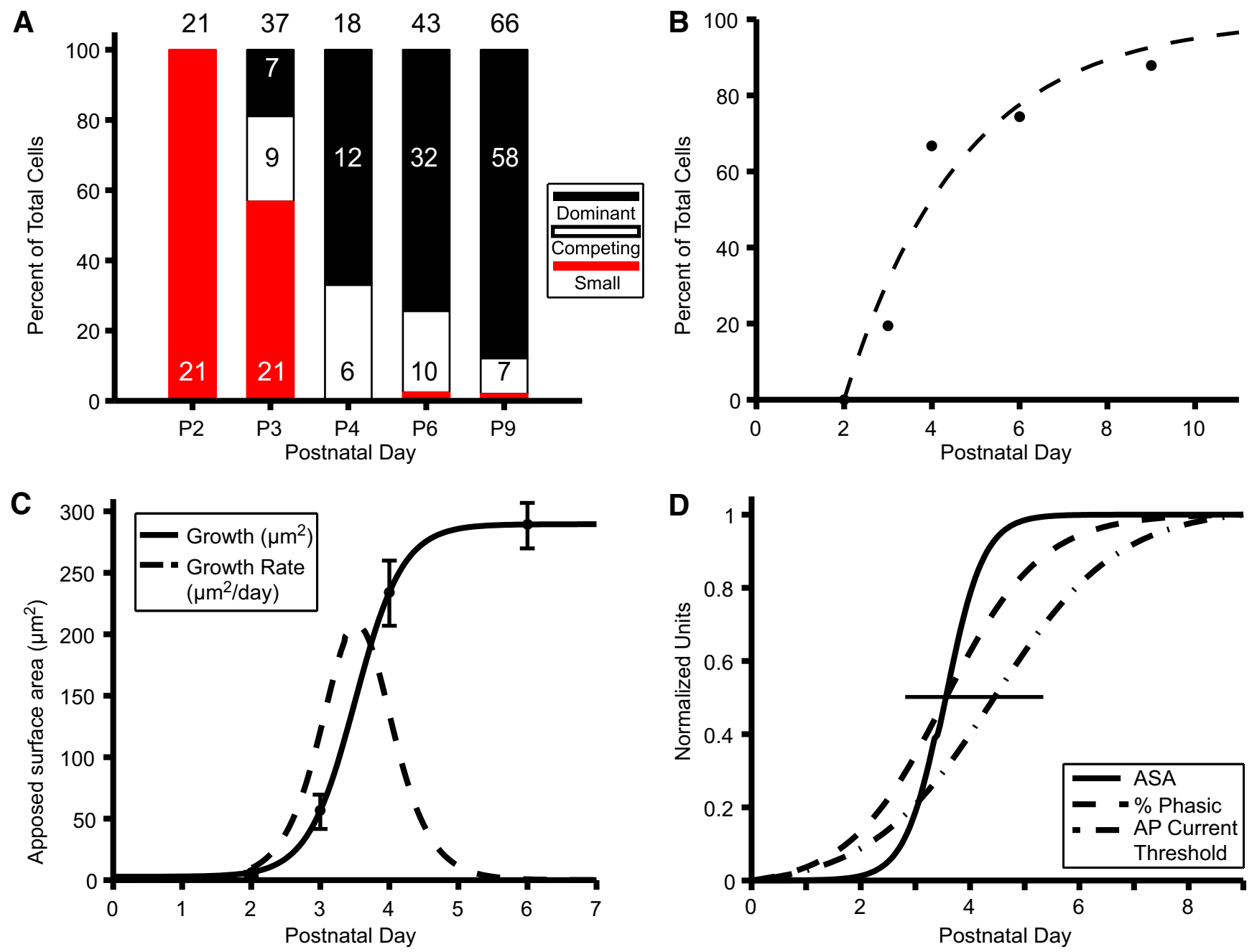

Figure 8. Competition and population growth dynamics of calycigenic terminals. $A$, Summary histograms of nerve terminal growth by prevalence of MNTB cells with inputs in the categories of (1) only small terminals (red), (2) actively competing large terminals (open; size ratio, $<5$ ), and (3) a dominant large input (black; size ratio, $>5$ ). Numbers of cells analyzed at each age indicated above histograms. $B$, Dynamics for emergence of a dominant large input. Exponential fit with $\tau=2.7 \mathrm{~d}, R^{2}=0.94$. C, Population growth dynamics for calyx-forming inputs. Data points are average of the largest terminal onto each reconstructed cell between $\mathrm{P} 2$ and P6; size of largest input at P9 was assessed qualitatively for most cells. At P6, cells with inputs $<75 \mu \mathrm{m}^{2}$ excluded from analysis as these likely formed a distinct population (see Results for P6 and P9). Data were fitted to a Boltzmann function as described in Materials and Methods. Slope of curve reveals growth rate, which peaks at $207 \mu \mathrm{m}^{2} /$ d. D, Coordinated time scales for calyx growth (Boltzmann fit from C, solid line), transition of AP firing phenotype from tonic to phasic (dashed line) and increase in AP threshold to current pulse injection (dash-dotted line) from Hoffpauir et al. (2010). Horizontal line indicates half-maximum of normalized ordinate values.
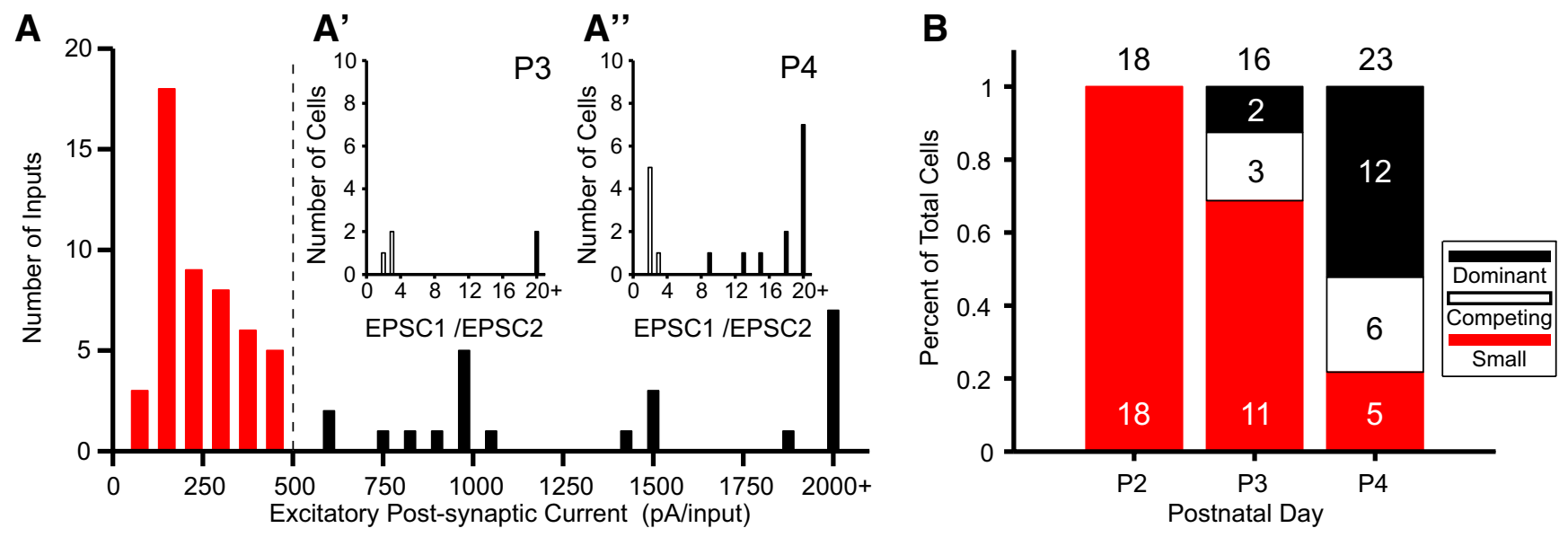

Figure 9. Electrophysiology methods underestimate innervation. $A$, Distribution of synaptic currents induced using minimal stimulation paradigm at $\mathrm{P} 3$ and $\mathrm{P4}$, reanalyzed from Hoffpauir et al. (2010). Dashed line indicates break in histogram at $500 \mathrm{pA} . \boldsymbol{A}^{\prime}, \boldsymbol{A}^{\prime \prime}$, Input size ratio [largest input (EPSC1)/second largest input (EPSC2)] shows groups of inputs with values $<5\left(\boldsymbol{A}^{\prime}, \boldsymbol{A}^{\prime \prime}, \boldsymbol{B}\right.$, open histogram bars) and $>5$ $\left(\boldsymbol{A}^{\prime}, \boldsymbol{A}^{\prime \prime}, \boldsymbol{B}\right.$, black histogram bars). $\boldsymbol{B}$, Dynamics for emergence of dominant large input, analyzed as for anatomical inputs in Figure $8 A$. Number of cells at each age indicated above histogram. 
puts onto cells at P3-P6 were mapped onto the postsynaptic surface and inspected for innervation of contiguous regions of the somatic surface. In all cases, actively competing inputs occupied segregated territories on the somatic surface (Fig. 10). The ASAs for three smaller, actively competing inputs (Fig. 10A, P3 cell) indicate that they begin their growth within well compartmentalized regions of the somatic surface. This segregation is maintained as competing inputs grow (Fig. 10B, different cell from P3 depicted) and can be located on opposite sides of the cell body (Fig. 10C, P6 cell). The closest contact between competing inputs in our dataset is illustrated in Figure $10 B$ (arrowhead), where extensions from the main region of ASA for each input nearly touch but remain on opposite sides of a somatic spicule. We next investigated whether glial incursions (Fig. 1C, white arrowheads) between calycigenic terminals and the somatic surface were in contact, considering that these glial processes better indicate the actual edges of the terminals and may mediate physical interactions. The contact areas between these glial incursions and the somatic surface are indicated in Figure $10 A^{\prime}, B^{\prime}, C^{\prime}$. These regions also remain segregated on the somatic surface.

\section{Discussion}

With this systematic analysis of highresolution structural images, we demonstrate that the innervation of MNTB principal neurons bears the hallmarks of initial exuberance and strengthening and pruning characteristic of other developing neural systems. A well timed growth spurt exceeding $200 \mu \mathrm{m}^{2} / \mathrm{d}$ during a single day at $\mathrm{P} 3$ is more constrained temporally than in other systems, such as CF:PC and NMJ, and offers opportunities to study growth and competition on a compressed time scale. In retrospect, this characteristic made possible this first application of SBEM to the developing brain at high temporal resolution.

\section{Experimental considerations}

We relied upon the distribution of terminal sizes to define large inputs ( $>25$ or $35 \mu \mathrm{m}^{2}$, depending upon age), and the presence of at least two large inputs as an estimate (50\% at P3) for the prevalence of competition. This is a minimal estimate because our $24 \mathrm{~h}$ sampling interval may miss a stage at which more MNTB cells are contacted by competing inputs, due to explosive growth of calycigenic terminals at P3. Note that changing the threshold for defining large inputs does not appreciably change the prevalence of competition ( $60 \%$ at $15 \mu \mathrm{m}^{2}$ to $43 \%$ at $\left.35 \mu \mathrm{m}^{2}\right)$, so this metric is neither sensitive to the method of defining threshold nor to its small variation across age. Therefore, we propose a qualitative model that incorporates both competition among large inputs and emergence of only a single large input from initial exuberant innervation (Fig. 11A).

We provided a refined definition of active competition based upon the input size ratio, considering that a large input may have
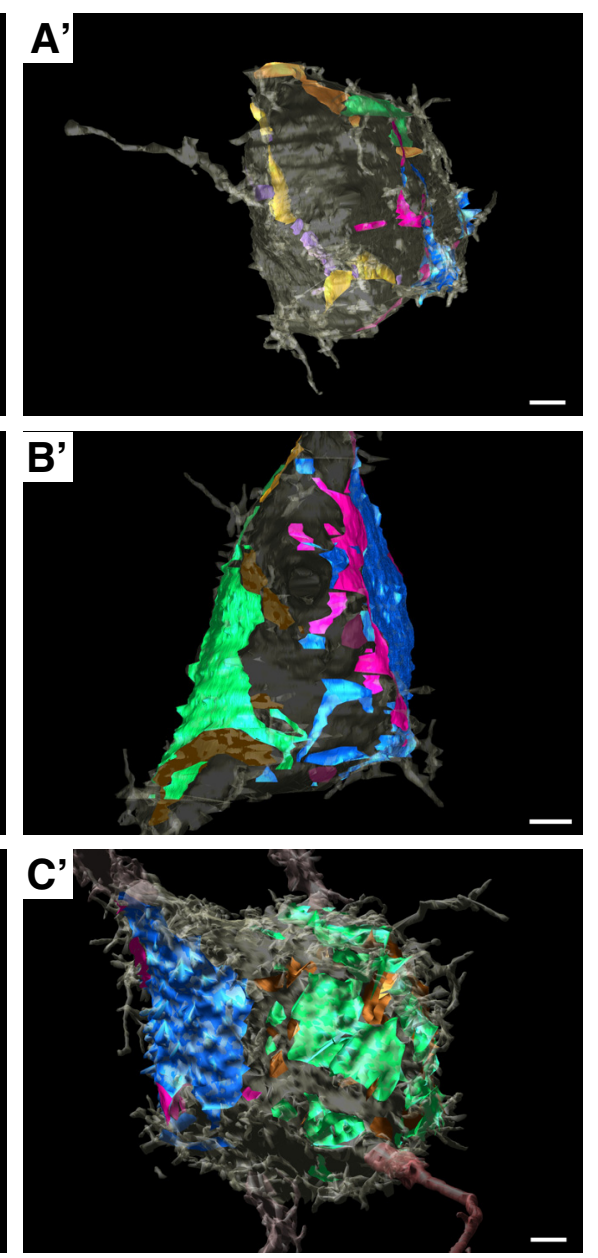

Figure 10. Competing inputs innervate distinct domains on MNTB somatic surface. $\boldsymbol{A}-\boldsymbol{C}$, Dotted lines hand drawn to illustrate well rgest yellow. $\boldsymbol{A}^{\prime}-\boldsymbol{C}^{\prime}$, Inputs are segregated even after addition of glial incursions under terminals (maroon for blue terminals; bronze for green terminals; purple for yellow terminal). Cell in $\boldsymbol{A}^{\prime}$ has green input and associated glial incursions located on opposite side of cell body, which is translucent, giving the illusion of overlap with maroon glial incursion. $\boldsymbol{A}-\boldsymbol{B}^{\prime}, \mathrm{P3}$ cells; $\boldsymbol{C}_{\boldsymbol{C}} \boldsymbol{C}^{\prime}, \mathrm{P} 6$ cell. Scale bars, $2 \mu \mathrm{m}$.

already lost the competition to a much larger input. Additional rules may have better-defined cells with actively competing inputs. For example, the largest input for some cells could be $>100 \mu \mathrm{m}^{2}$ larger than the second largest input, and considered to be the dominant large input; however, the ratio of input sizes $(<5)$ placed the cell into the actively competing category. Conversely, some cells had a single large input, classified as a dominant large input, that was relatively small $\left(<50 \mu \mathrm{m}^{2}\right)$, therefore close in size to the second largest input with which it could be in active competition. Very few cells and approximately equal numbers fell into these complementary borderline categories ( 1 in each category at P3 and P6; 2 in the first and 1 in the second category at $\mathrm{P} 4$ ), so this concern does not alter our conclusions.

The use of SBEM permitted well defined metrics for synaptic growth and competition because it revealed actual ASA. Light microscopic labeling of the calyx, including immunolabeling for synaptic vesicle proteins, overestimates its size due to glial incursions between the calycigenic terminals and MNTB cell (Fig. 1C; Rowland et al., 2000). SBEM also permitted tracking fine processes due to precise alignment between sequential images. The morphology of these inputs is in general agreement with previously published descriptions of the protocalyx and immature calyx (Morest, 1968; Kandler and Friauf, 1993), but with more 

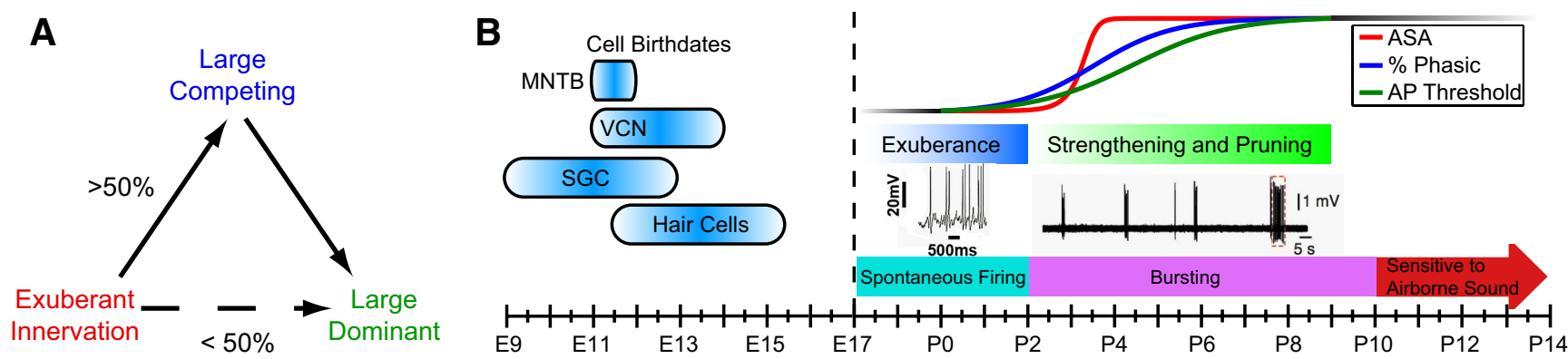

Figure 11. Summary models for dynamics of calyx growth and competition. $A$, Early exuberance at $\mathrm{P} 2$ leads to cells at $\mathrm{P} 3$ with multiple large inputs by strengthening and pruning to a large competing input phase in $50 \%$ of cells, or by direct emergence of dominant large calyces in $50 \%$ of cells. Since $24 \mathrm{~h}$ sampling interval may have missed competing inputs to some cells, these values are listed as minima and maxima, respectively. $\boldsymbol{B}$, Developmental setting for calyx growth. Cells of lower auditory system born by end of second embryonic week and cochlear activity can drive contralateral MNTB at E17. Based upon data and summary from Hoffpauir et al. (2010). Transition in cochlear activity from nonbursting to bursting patterns of activity (see references in text) is proposed to trigger rapid, synchronized presynaptic and postsynaptic maturation in the MNTB. Exuberance of innervation by small inputs gives way to strengthening and pruning of $2-3$ large inputs. Calyx growth and competition are largely resolved before the animals demonstrate sensitivity to airborne sound.

accurate 3D reconstruction due to efficient capture of thin processes. One limitation of SBEM is that the tissue volume is smaller than in some LM studies, although our more recently collected image volumes (Table 1, P2, P6, and P9) bridge this gap. Note that our analysis is more extensive and time-consuming than in previously published studies using SBEM or related techniques (Bock et al., 2011; Briggman et al., 2011), because we quantify contacts by ASA in 3D. One goal of nanoscale connectomics is to compare wiring diagrams between brains in different conditions (Seung, 2012). We have achieved an expression of this goal by comparing the same brain region at short temporal intervals across developmental age.

\section{The nature of competition}

Our data place constraints on the $\mathrm{CH}$ :MNTB competitive process and reveal similarities with other model systems. We were often able to trace small inputs at P2 to large-diameter calycigenic axons, noting that some inputs not traced to calycigenic axons may represent GABAergic or glycinergic inputs (Awatramani et al., 2005; Hoffpauir et al., 2010; Rusu and Borst, 2011). Convergence of $\geq 3-4$ small inputs from calycigenic axons is evidence for initial exuberance because only $2-3$ inputs strengthen to pass through a second pruning phase for monoinnervation. This process is similar to the RGC:dLGN, CF:PC, and NMJ systems, whereby tens of small inputs winnow to 2-3 (NMJ) or 5-7 larger inputs (CF:PC, NMJ) during a first phase of competition by strengthening a subset of inputs while pruning many others (Chedotal and Sotelo, 1992; Colman et al., 1997; Chen and Regehr, 2000; Sugihara, 2005; Tapia et al., 2012). After this first phase of strengthening and pruning in these systems, small inputs do not participate further in competition. Competition resolves to monoinnervation for most MNTB cells within $2 \mathrm{~d}$, similar to rapid emergence of a dominant input in the CF:PC system during the "nest" stage of innervation between P4 and P7 (Kano and Hashimoto, 2012). In the RGC:dLGN and NMJ systems, this final phase of competition is protracted, resolving over 1-2 weeks; growth of CFs along with the PC dendritic tree occupies a similar period of time (Brown et al., 1976; Balice-Gordon and Lichtman, 1993; Chen and Regehr, 2000).

Competition for the final one-third of MNTB cells resolves more slowly and is complete by P9 in all but a small subset of cells, consistent with physiological measures at P9-P11 (Bergsman et al., 2004). This group was spatially clustered at the margins of the MNTB, and may indicate a small subpopulation of MNTB cells that either proceed at a different developmental pace, remain multi-innervated, or disappear after hearing onset. These cells may elude detection by light microscopy in part because the summed area of all inputs can be large $\left(>200 \mu \mathrm{m}^{2}\right)$.

Our data also place a size limit on competitive inputs. At each age, at least one cell in the sample volume was contacted by two very large inputs of nearly equal size (Figs. $4 C, F, F ; 5 B, E, 6 C, E$ ), but these were never the largest inputs. Perhaps both competing inputs grew to such a large size in few cases, or elimination of "losing" inputs is a swift process. At the NMJ, the smaller of two large inputs can eventually out-compete the larger in a process referred to as "flip-flop" (Walsh and Lichtman, 2003). We cannot rule out this possibility for calyx innervation, but it is unlikely for cells that resolve a dominant input by $\mathrm{P} 4$ due to the rapid growth rate. For cells in which competition resolves more slowly after P4, "flip-flop" of actively competing inputs is more likely. In contrast to the NMJ (Bishop et al., 2004; Turney and Lichtman, 2012), once an axon has withdrawn contact from an MNTB cell, it is difficult to identify within the complex cellular arrangements of the MNTB. Processes of degeneration and their resemblance to other systems (Luo and O'Leary, 2005) will be presented in a subsequent report.

\section{Potential mediators of calyx growth and competition}

Calyx growth is integrated with other aspects of tissue reorganization in the MNTB. At P2, MNTB neurons are tightly packed, with much of their somatic surface apposed to other neurons or wrapped by glia. Somatic contact between principal cells and glial wrapping of the somatic surface is less prevalent at $\mathrm{P} 3$ and provides space for large terminals to innervate the somatic surface. These structural changes may be part of a process whereby neurons alter the composition of their cell membrane to disentangle from other cells and prime for synapse formation. Postsynaptic structural changes may form part of the maturation process, such as an apparent increased number of somatic spicules (compare Fig. 3B, inset, with Fig. $6 E$ ). Calyx growth closely parallels physiological transitions in the MNTB cell (Fig. 8C; Hoffpauir et al., 2010), suggestive of common initiating events. One trigger for these coordinated presynaptic and postsynaptic events may be transition from nonbursting spontaneous activity (Marrs and Spirou, 2012) to bursting patterns initiated in the cochlea and delivered by globular bushy cells to the MNTB (Tritsch and Bergles, 2010; Tritsch et al., 2010; Fig. 11B).

Accumulating evidence across multiple neural systems suggests that competitive winners are selected in an activitydependent process (Balice-Gordon and Lichtman, 1993; Buffelli 
et al., 2003; Hooks and Chen, 2006; Ohtsuki and Hirano, 2008; Favero et al., 2012) triggered by cell signaling pathways involving protein kinases (for review, see Watanabe and Kano, 2011) and possibly subject to global factors, such as metabolic load of the presynaptic neuron (Kasthuri and Lichtman, 2003). Actively competing calyces are also growing, indicating a level of support for both inputs by the MNTB cell. In contrast to the NMJ, where axons vie for a fixed postsynaptic receptor area (Turney and Lichtman, 2012), competing calycigenic inputs are segregated on the somatic surface (Fig. 10). This spatial organization may facilitate reinforcement via a Hebbian mechanism of inputs that stay ahead of the rapid and concurrent increase in AP threshold. Location of calyx-forming inputs on the somatic surface may be a determinant of the eventual winner, similar to early designation of the winning $\mathrm{CF}$ as the first to innervate the dendritic pole of the PC body (Hashimoto et al., 2009). Further investigation should include assessment of $\mathrm{CH}$ :MNTB growth dynamics across the entire frequency axis of the MNTB so that local competing mechanisms can be compared with global mechanisms, including mismatched chemical signals, such as Ephs and ephrins (Hsieh et al., 2010; Nakamura et al., 2012), as has been studied at the NMJ (Tapia et al., 2012).

In summary, the $\mathrm{CH}: \mathrm{MNTB}$ shares features with other model systems for neural development. A unique feature for the $\mathrm{CH}$ : MNTB is the more rapid occurrence of these developmental events and their completion before the onset of sensitivity to airborne sound between P10 and P12 (Ehret, 1976; Romand and Ehret, 1990; Kamiya et al., 2001; Sonntag et al., 2009). This compressed time frame has made possible precise quantification of population growth dynamics and may offer experimental advantages to decipher cellular mechanisms for synaptic growth and competition.

\section{Notes}

This article has associated cover videos.
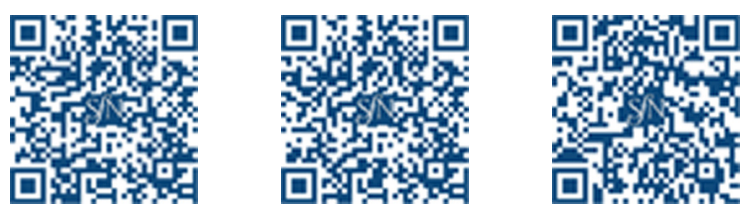

\section{References}

Awatramani GB, Turecek R, Trussell LO (2005) Staggered development of GABAergic and glycinergic transmission in the MNTB. J Neurophysiol 93:819-828. Medline

Balice-Gordon RJ, Lichtman JW (1990) In vivo visualization of the growth of pre- and postsynaptic elements of neuromuscular junctions in the mouse. J Neurosci 10:894-908. Medline

Balice-Gordon RJ, Lichtman JW (1993) In vivo observations of pre- and postsynaptic changes during the transition from multiple to single innervation at developing neuromuscular junctions. J Neurosci 13:834-855. Medline

Banks MI, Smith PH (1992) Intracellular recordings from neurobiotinlabeled cells in brain slices of the rat medial nucleus of the trapezoid body. J Neurosci 12:2819-2837. Medline

Bergsman JB, De Camilli P, McCormick DA (2004) Multiple large inputs to principal cells in the mouse medial nucleus of the trapezoid body. J Neurophysiol 92:545-552. CrossRef Medline

Bishop DL, Misgeld T, Walsh MK, Gan WB, Lichtman JW (2004) Axon branch removal at developing synapses by axosome shedding. Neuron 44:651-661. CrossRef Medline

Bock DD, Lee WC, Kerlin AM, Andermann ML, Hood G, Wetzel AW, Yurgenson S, Soucy ER, Kim HS, Reid RC (2011) Network anatomy and in vivo physiology of visual cortical neurons. Nature 471:177-182. CrossRef Medline
Borst JG, Soria van Hoeve J (2012) The calyx of held synapse: from model synapse to auditory relay. Annu Rev Physiol 74:199-224. CrossRef Medline

Briggman KL, Helmstaedter M, Denk W (2011) Wiring specificity in the direction-selectivity circuit of the retina. Nature 471:183-188. CrossRef Medline

Brown MC, Jansen JK, Van Essen D (1976) Polyneuronal innervation of skeletal muscle in new-born rats and its elimination during maturation. J Physiol 261:387-422. Medline

Buffelli M, Burgess RW, Feng G, Lobe CG, Lichtman JW, Sanes JR (2003) Genetic evidence that relative synaptic efficacy biases the outcome of synaptic competition. Nature 424:430-434. CrossRef Medline

Chedotal A, Sotelo C (1992) Early development of olivocerebellar projections in the fetal rat using CGRP immunocytochemistry. Eur J Neurosci 4:1159-1179. CrossRef Medline

Chen C, Regehr WG (2000) Developmental remodeling of the retinogeniculate synapse. Neuron 28:955-966. CrossRef Medline

Colman H, Nabekura J, Lichtman JW (1997) Alterations in synaptic strength preceding axon withdrawal. Science 275:356-361. CrossRef Medline

Denk W, Horstmann H (2004) Serial block-face scanning electron microscopy to reconstruct three-dimensional tissue nanostructure. PLoS Biol 2:e329. CrossRef Medline

Ehret G (1976) Development of absolute auditory thresholds in the house mouse (Mus musculus). J Am Audiol Soc 1:179-184. Medline

Favero M, Busetto G, Cangiano A (2012) Spike timing plays a key role in synapse elimination at the neuromuscular junction. Proc Natl Acad Sci U S A 109:E1667-E1675. CrossRef Medline

Ford MC, Grothe B, Klug A (2009) Fenestration of the calyx of Held occurs sequentially along the tonotopic axis, is influenced by afferent activity, and facilitates glutamate clearance. J Comp Neurol 514:92-106. CrossRef Medline

Forsythe ID, Barnes-Davies M (1993) The binaural auditory pathway: excitatory amino acid receptors mediate dual timecourse excitatory postsynaptic currents in the rat medial nucleus of the trapezoid body. Proc Biol Sci 251:151-157. CrossRef Medline

Friauf E, Ostwald J (1988) Divergent projections of physiologically characterized rat ventral cochlear nucleus neurons as shown by intra-axonal injection of horseradish peroxidase. Exp Brain Res 73:263-284. Medline

Futai K, Okada M, Matsuyama K, Takahashi T (2001) High-fidelity transmission acquired via a developmental decrease in NMDA receptor expression at an auditory synapse. J Neurosci 21:3342-3349. Medline

Hashimoto K, Ichikawa R, Kitamura K, Watanabe M, Kano M (2009) Translocation of a "winner" climbing fiber to the Purkinje cell dendrite and subsequent elimination of "losers" from the soma in developing cerebellum. Neuron 63:106-118. CrossRef Medline

Hoffpauir BK, Grimes JL, Mathers PH, Spirou GA (2006) Synaptogenesis of the calyx of Held: rapid onset of function and one-to-one morphological innervation. J Neurosci 26:5511-5523. CrossRef Medline

Hoffpauir BK, Kolson DR, Mathers PH, Spirou GA (2010) Maturation of synaptic partners: functional phenotype and synaptic organization tuned in synchrony. J Physiol 588:4365-4385. CrossRef Medline

Hollander M, Wolfe D (1999) Nonparametric statistical methods, 2nd ed. New York: Wiley.

Hong YK, Chen C (2011) Wiring and rewiring of the retinogeniculate synapse. Curr Opin Neurobiol 21:228-237. CrossRef Medline

Hooks BM, Chen C (2006) Distinct roles for spontaneous and visual activity in remodeling of the retinogeniculate synapse. Neuron 52:281-291. CrossRef Medline

Hsieh CY, Nakamura PA, Luk SO, Miko IJ, Henkemeyer M, Cramer KS (2010) Ephrin-B reverse signaling is required for formation of strictly contralateral auditory brainstem pathways. J Neurosci 30:9840-9849. CrossRef Medline

Kamiya K, Takahashi K, Kitamura K, Momoi T, Yoshikawa Y (2001) Mitosis and apoptosis in postnatal auditory system of the $\mathrm{C} 3 \mathrm{H} / \mathrm{He}$ strain. Brain Res 901:296-302. CrossRef Medline

Kandler K, Friauf E (1993) Pre- and postnatal development of efferent connections of the cochlear nucleus in the rat. J Comp Neurol 328:161-184. CrossRef Medline

Kano M, Hashimoto K (2012) Activity-dependent maturation of climbing fiber to Purkinje cell synapses during postnatal cerebellar development. Cerebellum 11:449-450. CrossRef Medline 
Kasthuri N, Lichtman JW (2003) The role of neuronal identity in synaptic competition. Nature 424:426-430. CrossRef Medline

Kleinfeld D, Bharioke A, Blinder P, Bock DD, Briggman KL, Chklovskii DB, Denk W, Helmstaedter M, Kaufhold JP, Lee WC, Meyer HS, Micheva KD, Oberlaender M, Prohaska S, Reid RC, Smith SJ, Takemura S, Tsai PS, Sakmann B (2011) Large-scale automated histology in the pursuit of connectomes. J Neurosci 31:16125-16138. CrossRef Medline

Kuwabara N, DiCaprio RA, Zook JM (1991) Afferents to the medial nucleus of the trapezoid body and their collateral projections. J Comp Neurol 314:684-706. CrossRef

Luo L, O'Leary DD (2005) Axon retraction and degeneration in development and disease. Annu Rev Neurosci 28:127-156. CrossRef Medline

Marrs GS, Spirou GA (2012) Embryonic assembly of auditory circuits: spiral ganglion and brainstem. J Physiol 590:2391-2408. Medline

Mattox DE, Neises GR, Gulley RL (1982) A freeze-fracture study of the maturation of synapses in the anteroventral cochlear nucleus of the developing rat. Anat Rec 204:281-287. CrossRef Medline

Morest D (1968) The growth of synaptic endings in the mammalian brain: a study of the calyces of the trapezoid body. Anat Embryol 127:201-220. CrossRef

Nakamura PA, Hsieh CY, Cramer KS (2012) EphB signaling regulates target innervation in the developing and deafferented auditory brainstem. Dev Neurobiol 72:1243-1255. CrossRef Medline

Ohtsuki G, Hirano T (2008) Bidirectional plasticity at developing climbing fiber-Purkinje neuron synapses. Eur J Neurosci 28:2393-2400. CrossRef Medline

Peters A, Palay S, Webster H (1991) The fine structure of the nervous system: neurons and their supporting cells, 3rd ed. New York: Oxford UP.

Pologruto TA, Sabatini BL, Svoboda K (2003) ScanImage: flexible software for operating laser scanning microscopes. Biomed Eng Online 2:13. CrossRef Medline

Purves D, Lichtman J (1980) Elimination of synapses in the developing nervous system. Science 210:153-157. CrossRef Medline

Rodríguez-Contreras A, de Lange RP, Lucassen PJ, Borst JG (2006) Branching of calyceal afferents during postnatal development in the rat auditory brainstem. J Comp Neurol 496:214-228. CrossRef Medline

Rodríguez-Contreras A, van Hoeve JS, Habets RL, Locher H, Borst JG (2008) Dynamic development of the calyx of Held synapse. Proc Natl Acad Sci U S A 105:5603-5608. CrossRef Medline

Romand R, Ehret G (1990) Development of tonotopy in the inferior colliculus. I. Electrophysiological mapping in house mice. Brain Res Dev Brain Res 54:221-234. CrossRef Medline

Rowland KC, Irby NK, Spirou GA (2000) Specialized synapse-associated structures within the calyx of Held. J Neurosci 20:9135-9144. Medline

Rusu SI, Borst JG (2011) Developmental changes in intrinsic excitability of principal neurons in the rat medial nucleus of the trapezoid body. Dev Neurobiol 71:284-295. CrossRef Medline

Seung S (2012) Connectome: how the brain's wiring makes us who we are, 1st ed. Boston: Houghton Mifflin Harcourt.

Smith PH, Joris PX, Carney LH, Yin TC (1991) Projections of physiologi- cally characterized globular bushy cell axons from the cochlear nucleus of the cat. J Comp Neurol 304:387-407. CrossRef Medline

Sonntag M, Englitz B, Kopp-Scheinpflug C, Rübsamen R (2009) Early postnatal development of spontaneous and acoustically evoked discharge activity of principal cells of the medial nucleus of the trapezoid body: an in vivo study in mice. J Neurosci 29:9510-9520. CrossRef Medline

Spirou GA, Brownell WE, Zidanic M (1990) Recordings from cat trapezoid body and HRP labeling of globular bushy cell axons. J Neurophysiol 63: 1169-1190. Medline

Sugihara I (2005) Microzonal projection and climbing fiber remodeling in single olivocerebellar axons of newborn rats at postnatal days 4-7. J Comp Neurol 487:93-106. CrossRef Medline

Tapia JC, Wylie JD, Kasthuri N, Hayworth KJ, Schalek R, Berger DR, Guatimosim C, Seung HS, Lichtman JW (2012) Pervasive synaptic branch removal in the mammalian neuromuscular system at birth. Neuron 74 816-829. CrossRef Medline

Tritsch NX, Bergles DE (2010) Developmental regulation of spontaneous activity in the mammalian cochlea. J Neurosci 30:1539-1550. CrossRef Medline

Tritsch NX, Rodríguez-Contreras A, Crins TT, Wang HC, Borst JG, Bergles DE (2010) Calcium action potentials in hair cells pattern auditory neuron activity before hearing onset. Nat Neurosci 13:1050-1052. CrossRef Medline

Turney SG, Lichtman JW (2012) Reversing the outcome of synapse elimination at developing neuromuscular junctions in vivo: evidence for synaptic competition and its mechanism. PLoS Biol 10:e1001352. CrossRef Medline

Vaughn JE (1989) Fine structure of synaptogenesis in the vertebrate central nervous system. Synapse 3:255-285. CrossRef Medline

Walsh MK, Lichtman JW (2003) In vivo time-lapse imaging of synaptic takeover associated with naturally occurring synapse elimination. Neuron 37:67-73. CrossRef Medline

Warr WB (1972) Fiber degeneration following lesions in the multipolar and globular cell areas in the ventral cochlear nucleus of the cat. Brain Res 40:247-270. CrossRef Medline

Watanabe M, Kano M (2011) Climbing fiber synapse elimination in cerebellar Purkinje cells. Eur J Neurosci 34:1697-1710. CrossRef Medline

Wilke SA, Antonios JK, Bushong EA, Badkoobehi A, Malek E, Hwang M, Terada M, Ellisman MH, Ghosh A (2013) Deconstructing complexity: serial block-face electron microscopic analysis of the hippocampal mossy fiber synapse. J Neurosci 33:507-522. CrossRef Medline

Wu H, Xiong WC, Mei L (2010) To build a synapse: signaling pathways in neuromuscular junction assembly. Development 137:1017-1033. CrossRef Medline

Yang S, Adhikari S, Dobbala M, Adusumilli S, Rowley JD, Ganikhanov F, Zhang L, Marrs G, Wysolmerski R, Spirou G (2013) Multi-color ultrafast laser platform for nonlinear optical imaging based on independently tunable optical parametric oscillators. Appl Phys B. Advance online publication. Retrieved March 4, 2013. doi:10.1007/s00340-013-5381-x. CrossRef 